\title{
Integrating Federal and State Data Records to Report Progress in Establishing Agricultural Conservation Practices on Chesapeake Bay Farms
}

By W. Dean Hively, Olivia H. Devereux, and Peter Claggett

Open-File Report 2013-1287 


\title{
U.S. Department of the Interior SALLY JEWELL, Secretary
}

\section{U.S. Geological Survey Suzette M. Kimball, Acting Director}

\author{
U.S. Geological Survey, Reston, Virginia: 2013
}

For more information on the USGS - the Federal source for science about the Earth, its natural and living resources, natural hazards, and the environment, visit http://www.usgs.gov or call 1-888-ASK-USGS.

For an overview of USGS information products, including maps, imagery, and publications, visit http://www.usgs.gov/pubprod

To order this and other USGS information products, visit http://store.usgs.gov

Any use of trade, firm, or product names is for descriptive purposes only and does not imply endorsement by the U.S. Government.

Although this information product, for the most part, is in the public domain, it also may contain copyrighted materials as noted in the text. Permission to reproduce copyrighted items must be secured from the copyright owner.

Suggested citation:

Hively, W.D., Devereux, 0.H., and Claggett, Peter, 2013, Integrating Federal and State data records to report progress in establishing agricultural conservation practices on Chesapeake Bay farms: U.S. Geological Survey Open-File Report 2013-1287, 36 p., http://dx.doi.org/10.3133/ofr20131287. 


\section{Foreword}

Introductory comments from collaborators at the Natural Resources Conservation Service:

United States Department of Agriculture

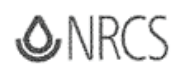

Recent years have shown increasing focus on the establishment of resource management systems to protect natural resources and maintain production capacity. Since its establishment, the United States Department of Agriculture (USDA) Natural Resources Conservation Service (NRCS) has been a strong provider of farm conservation planning and implementation. In the 2008 Farm Bill, the Chesapeake Bay watershed received enhanced funding ( $\$ 188 \mathrm{M}$ over five years) to target agricultural conservation practices to priority watersheds. And the 2009 Executive Order for Chesapeake Bay Protection and Restoration has promoted cooperation among federal and state agencies and non-governmental organizations working to restore water quality in the Chesapeake Bay watershed.

The Chesapeake Bay Program Partnership has provided a forum in which Federal and State agencies, along with farmers and municipalities and non-governmental organizations that developed, coordinated and implemented strategies for managing resources and improving water quality. In 2010, NRCS entered a partnership with the United States Geological Survey (USGS) establishing USGS as a Conservation Cooperator with privacy-protected access to USDA farmland datasets. The USGS, as an impartial scientific third party, has coordinated with the NRCS and the Chesapeake Bay Program Partnership and assisted in the compilation of an accurate, comprehensive dataset that has been well integrated with the jurisdictional datasets that are also used to assess, track, and report progress in conservation practice implementation. In addition to the USGS, the USDA has supported the establishment of Conservation Cooperator Agreements with the various jurisdictional agencies that support conservation implementation. NRCS participates in these agreements to facilitate agricultural producers receiving appropriate recognition for their conservation practices. NRCS role was to provide the data for this report and NRCS does support continued use of its data for acknowledgement of the environmental improvement effects resulting from conservation practice implementation.

We appreciate the role and expertise provided by USGS in supporting the effort to improve the accuracy and completeness of conservation datasets in the Chesapeake Bay watershed. Consistent and thorough reporting of NRCS supported conservation practices will be beneficial to the Chesapeake Bay Program jurisdictions in their efforts to quantify progress toward their conservation goals. In addition, with this information, the federal and state partnership can better target future conservation activities and funding. We want to ensure that producers' conservation activities on agricultural lands are fully acknowledged, support adaptive management of conservation programs to promote effective solutions, and address resource concerns while promoting sustainable agricultural practices.
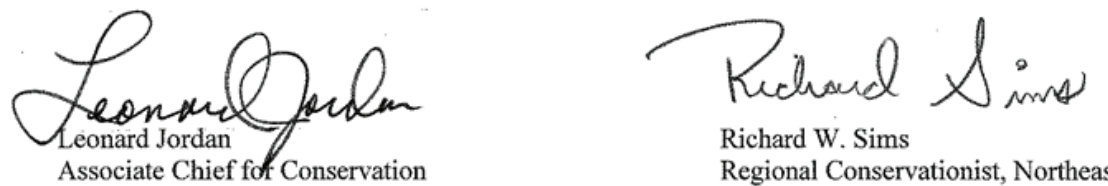

Richard W. Sims

Regional Conservationist, Northeast 


\section{Contents}

Abstract

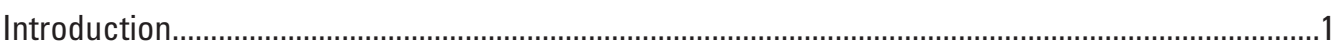

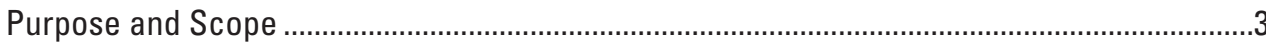

Data Confidentiality: USDA 1619 Conservation Cooperator Agreements .........................................

Section 1619 Agreements: Existing Language in the Jurisdictions..........................................

USGS Section 1619 Agreements for the Chesapeake Bay Watershed ....................................6

Data Access for the Chesapeake Bay Program Partnership's Annual Progress Review........8

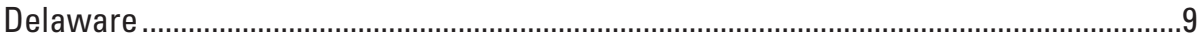

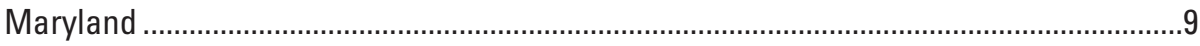

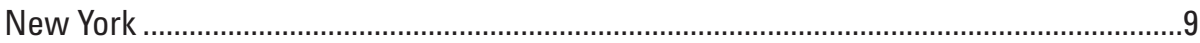

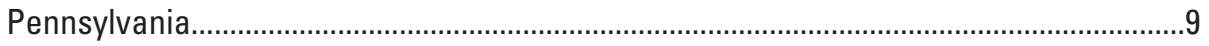

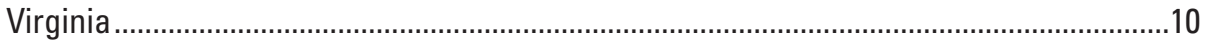

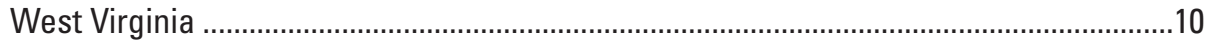

Establishing new 1619 Conservation Cooperator Agreements ................................................10

Data Collection and Processing ..........................................................................................12

Implementing Agricultural Conservation Practices..............................................................13

Documenting Agricultural Conservation Practices ...............................................................14

Obtaining USDA Agricultural Conservation Practice Data....................................................15

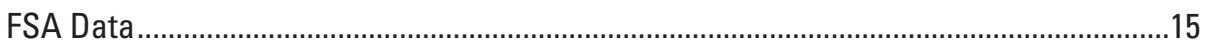

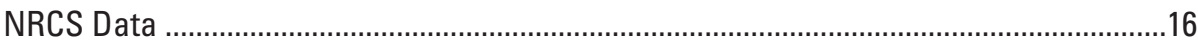

Removing Duplication Between NRCS and FSA Data Sources .............................................18

Data Aggregation To Protect Farmer Privacy ......................................................................19

Transmittal of Datasets to the State Jurisdictions ...........................................................19

Crosswalk Between USDA Practices and Chesapeake Bay Program Definitions..................20

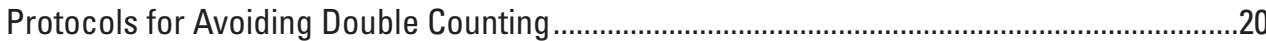

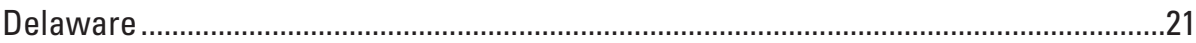

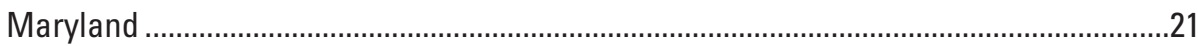

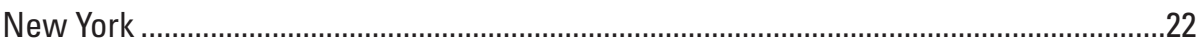

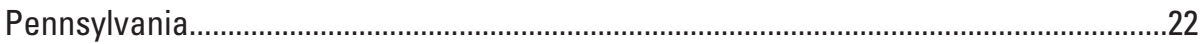

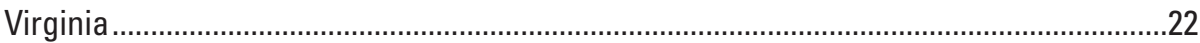

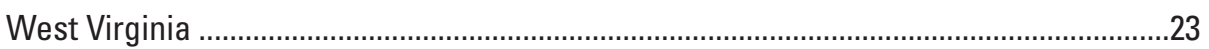

Final Submission of 2012 Conservation Data to the Annual Progress Review.......................23

2013 and Onward: The Drawing Board for Further Improvements.................................................23

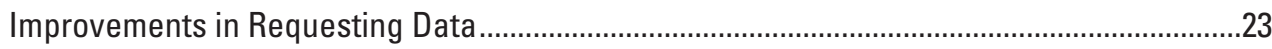

More Comprehensive Tracking of Practices by the USDA .................................................24

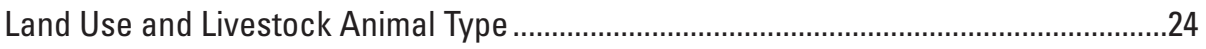

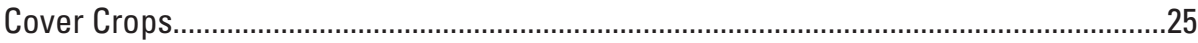

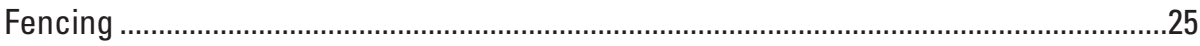

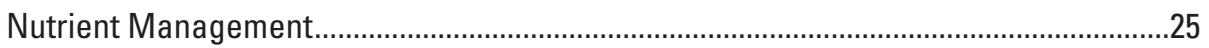

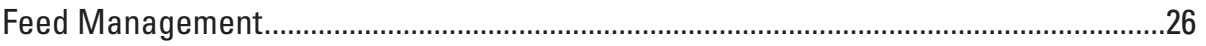

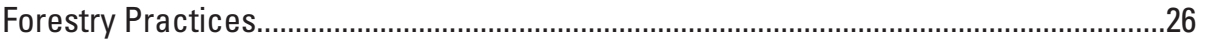

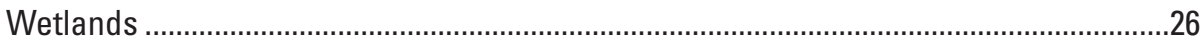

Tillage 


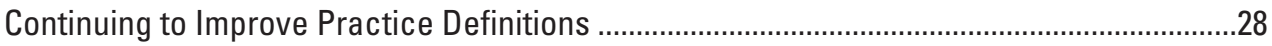

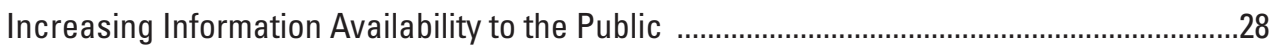

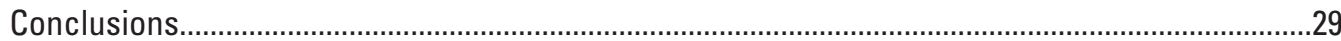

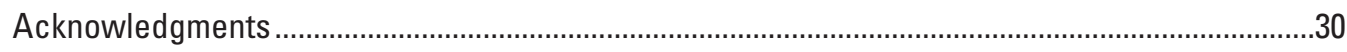

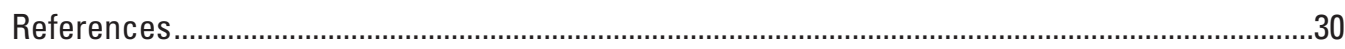

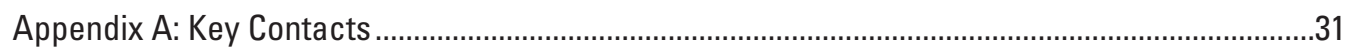

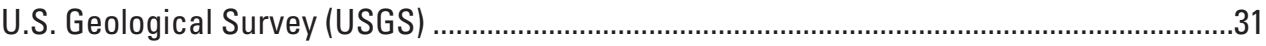

U.S. Department of Agriculture, Farm Service Agency (FSA) ................................................31

U.S. Department of Agriculture, Natural Resources Conservation Service (NRCS) ...............31

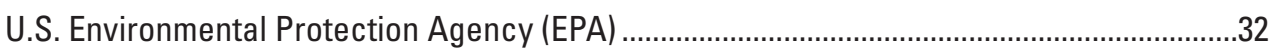

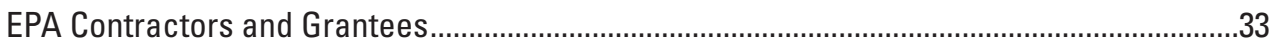

State Agencies

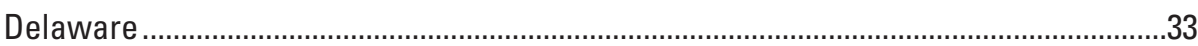

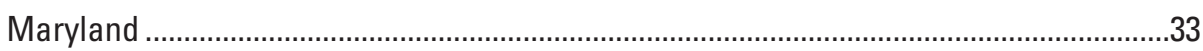

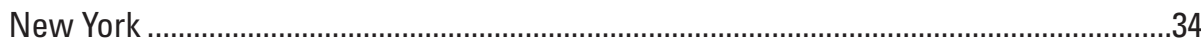

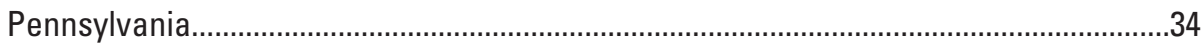

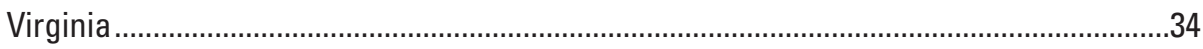

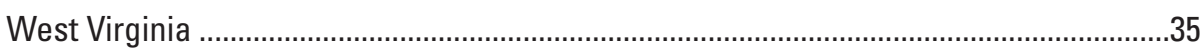

Appendix B: 1619 Conservation Cooperator Agreements............................................................35

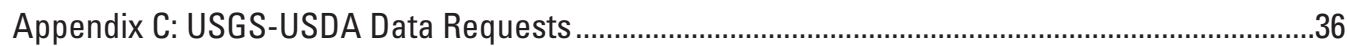

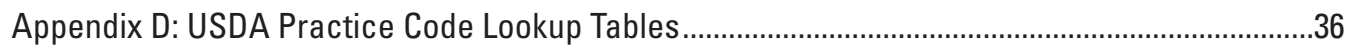

Appendix E: Crosswalk Between USDA Practice Codes and

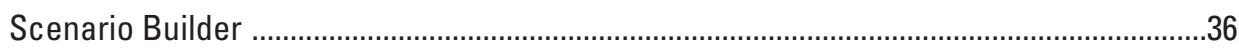

\section{Figures}

1. The Chesapeake Bay watershed (gray) with State jurisdictional borders (heavy black lines), and county boundaries (light black lines). The Chesapeake Bay watershed boundary is derived from the Chesapeake Bay Program Partnership's Watershed Model version 5.3.

2. Flow diagram of USDA conservation data collection and reporting strategies. See page viii of text for abbreviations.

\section{Tables}

1. Status of 1619 Conservation Cooperator Agreements for each Chesapeake Bay jurisdiction. These agreements facilitate access to USDA agricultural conservation data on a privacy protected basis. See page viii in text for agency abbreviations. Two jurisdictions (Delaware and Pennsylvania) do not currently have 1619 agreements in place.

2. State jurisdictional agencies that have been approved by the USDA for participation in 1619 data-sharing agreements to support the objectives of the NRCS Chesapeake Bay Watershed Initiative and increase the capacity for consistent, integrated analysis and reporting of conservation practice implementation data for the Chesapeake Bay watershed. See page viii of text for agency abbreviations. 
3. Number of USDA conservation practice records within each contract program, after removal of duplication between NRCS and FSA datasets (cleaned). These totals include all practices within counties that intersect or are contained within the Chesapeake Bay watershed and are for the 2012 progress year (July 1, 2011-June 30, 2012).

4. List of practices where FSA provided financial assistance and NRCS provided technical assistance

5. Possibilities for improved recordkeeping for USDA conservation practices ..................27

\section{Conversion Factors}

Inch/Pound to SI

\begin{tabular}{|c|c|c|}
\hline Multiply & By & To obtain \\
\hline \multicolumn{3}{|c|}{ Length } \\
\hline mile (mi) & 1.609 & kilometer (km) \\
\hline \multicolumn{3}{|c|}{ Area } \\
\hline acre & 4,047 & square meter $\left(\mathrm{m}^{2}\right)$ \\
\hline acre & 0.4047 & hectare (ha) \\
\hline
\end{tabular}

SI to Inch/Pound

\begin{tabular}{llll}
\hline \multicolumn{1}{c}{ Multiply } & \multicolumn{1}{c}{ By } & To obtain \\
\hline \multicolumn{2}{c}{ Length } & \\
\hline meter $(\mathrm{m})$ & 3.281 & foot $(\mathrm{ft})$ \\
kilometer $(\mathrm{km})$ & 0.6214 & mile $(\mathrm{mi})$ \\
\hline \multicolumn{2}{c}{ Area } \\
\hline square meter $\left(\mathrm{m}^{2}\right)$ & 0.0002471 & acre \\
hectare $($ ha) & 2.471 & acre &
\end{tabular}

Horizontal coordinate information is referenced to the North American Datum of 1983 (NAD 83). 


\section{Abbreviations}

\begin{tabular}{|c|c|}
\hline AMAP & NRCS Agricultural Management Assistance Program \\
\hline AWEP & NRCS Agricultural Water Enhancement Program \\
\hline BMP & Best Management Practices \\
\hline CBP Partnership & Chesapeake Bay Program Partnership \\
\hline CBRAP & Chesapeake Bay Regulatory and Accountability Program \\
\hline CBWI & NRCS Chesapeake Bay Watershed Initiative \\
\hline CDSI & NRCS Conservation Delivery Streamlining Initiative \\
\hline CLU & FSA Common Land Unit polygon shapefiles \\
\hline CRP & FSA Conservation Reserve Program \\
\hline CREP & FSA Conservation Reserve Enhancement Program \\
\hline CTA & NRCS Conservation Technical Assistance \\
\hline DE-DA & Delaware Department of Agriculture \\
\hline DE-DNREC & Delaware Department of Natural Resources and Environmental Control \\
\hline DE-FS & Delaware Forest Service \\
\hline EPA & U.S. Environmental Protection Agency \\
\hline EQIP & NRCS Environmental Quality Incentives Program \\
\hline FSA & USDA Farm Service Agency \\
\hline GIS & Geographic Information Systems \\
\hline IDEA & NRCS Integrated Data for Enterprise Analysis \\
\hline MDA & Maryland Department of Agriculture \\
\hline MDE & Maryland Department of the Environment \\
\hline MIDAS & FSA Modernize and Innovate the Delivery of Agricultural Systems project \\
\hline NEIEN & National Environmental Information Exchange Network \\
\hline NCP & NRCS National Conservation Planning database \\
\hline NRCS & USDA Natural Resources Conservation Service \\
\hline NYS & New York State \\
\hline NY-AEM & New York Agricultural Environmental Management Program \\
\hline NY-DEC & New York Department of Environmental Conservation \\
\hline PA-DA & Pennsylvania Department of Agriculture \\
\hline PA-DEP & Pennsylvania Department of Environmental Protection \\
\hline PII & Personally identifiable information \\
\hline PLANT & Lancaster County, PA, Planning and Tracking Portal \\
\hline PRS & NRCS Performance Results System database \\
\hline REAP & NRCS Resource Economics, Analysis and Policy Division \\
\hline SCIMS & USDA Service Center Information Management System \\
\hline TMDL & Total Maximum Daily Load \\
\hline USC & Upper Susquehanna Coalition \\
\hline USDA & U.S. Department of Agriculture \\
\hline USGS & U.S. Geological Survey \\
\hline VA-DCR & Virginia Department of Conservation and Recreation \\
\hline VA-DEQ & Virginia Department of Environmental Quality \\
\hline WHIP & NRCS Wildlife Habitat Incentive Program \\
\hline WQGIT & CBP Partnership's Water-quality Goal Implementation Team \\
\hline WVCA & West Virginia Conservation Agency \\
\hline WVDA & West Virginia Department of Agriculture \\
\hline WVDEP & West Virginia Department of Environmental Protection \\
\hline
\end{tabular}





\title{
Integrating Federal and State Data Records to Report Progress in Establishing Agricultural Conservation Practices on Chesapeake Bay Farms
}

\author{
By W. Dean Hively, Olivia H. Devereux, and Peter Claggett
}

\begin{abstract}
In response to the Executive Order for Chesapeake Bay Protection and Restoration (E.O. \#13508, May 12, 2009), the U.S. Geological Survey (USGS) took on the task of acquiring and assessing agricultural conservation practice data records for U.S. Department of Agriculture (USDA) programs, and transferred those datasets in aggregated format to State jurisdictional agencies for use in reporting conservation progress to the Chesapeake Bay Program Partnership (CBP Partnership). Under the guidelines and regulations that have been developed to protect and restore water-quality in the Chesapeake Bay, the six State jurisdictions that fall within the Chesapeake Bay watershed are required to report their progress in promoting agricultural conservation practices to the CBP Partnership on an annual basis. The installation and adoption of agricultural best management practices is supported by technical and financial assistance from both Federal and State conservation programs. The farm enrollment data for USDA conservation programs are confidential, but agencies can obtain access to the privacy-protected data if they are established as USDA Conservation Cooperators. The datasets can also be released to the public if they are first aggregated to protect farmer privacy. In 2012, the USGS used its Conservation Cooperator status to obtain implementation data for conservation programs sponsored by the USDA Natural Resources Conservation Service (NRCS) and the USDA Farm Service Agency (FSA) for farms within the Chesapeake Bay watershed. Three jurisdictions (Delaware, Pennsylvania, and West Virginia) used the USGS-provided aggregated dataset to report conservation progress in 2012, whereas the remaining three jurisdictions (Maryland, New York, and Virginia) used jurisdictional Conservation Cooperator Agreements to obtain privacy-protected data directly from the USDA. This report reviews the status of conservation data sharing between the USDA and the various jurisdictions, discusses the methods that were used by the USGS in 2012 to collect and process USDA agricultural conservation data, and also documents methods that were used by the jurisdictions to integrate Federal and State data records, reduce double counting, and provide an accurate reporting of conservation practices to the CBP Partnership's Annual Progress Review. A similar tracking, reporting, and assessment will occur in future years, as State and Federal governments and nongovernmental organizations continue to work with farmers and conservation districts to reduce the impacts of agriculture on water-quality.
\end{abstract}

\section{Introduction}

The Chesapeake Bay watershed includes parts of six State jurisdictions-Delaware (DE), Maryland (MD), New York (NY), Pennsylvania (PA), Virginia (VA), and West Virginia (WV) - as well as the District of Columbia (DC). The Chesapeake Bay watershed (fig. 1) extends over 64,000 square miles and has the largest water-to-land ratio of any estuary in the world. Waterquality is impaired in 97 percent of the Chesapeake Bay estuary and its tidal tributaries because of the impacts of human population, land use, and development (U.S. Environmental Protection Agency, 2010). Agricultural land use has been identified as a large contributor of nutrient, sediment, and chemical nonpoint-source pollution to the estuary. Accordingly, there is a large and coordinated effort to restore water-quality through the use of conservation practices on agricultural lands. These practices can be implemented through financial assistance programs sponsored by U.S. Department of Agriculture (USDA) agencies, by the jurisdictions, or on a voluntary basis.

The Chesapeake Bay watershed State jurisdictions are required (U.S. Environmental Protection Agency, 2009) to report conservation practice implementation on an annual basis to the EPA Chesapeake Bay Program Office and the Chesapeake Bay 


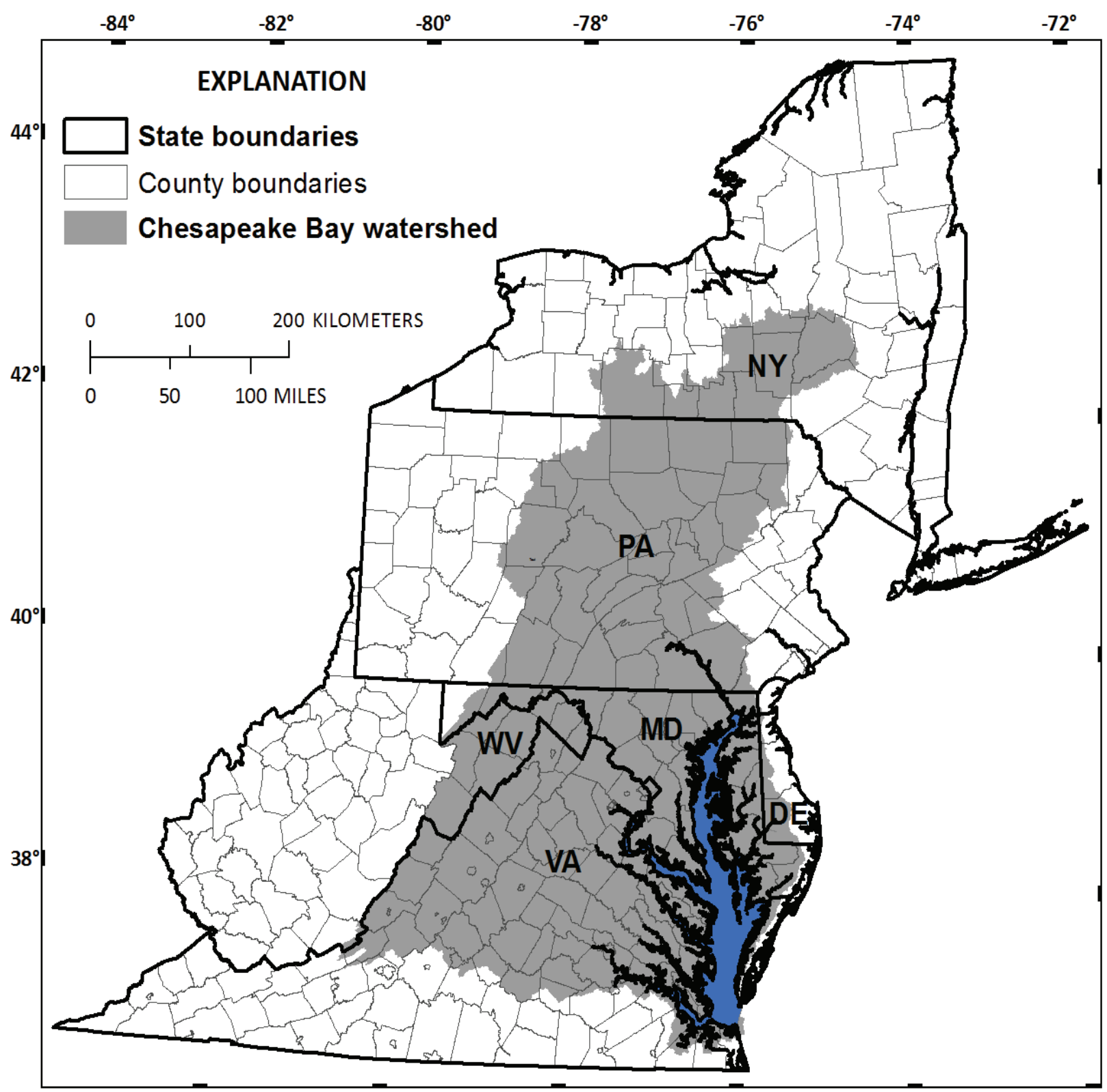

Figure 1. The Chesapeake Bay watershed (gray) with State jurisdictional borders (heavy black lines), and county boundaries (light black lines). The Chesapeake Bay watershed boundary is derived from the Chesapeake Bay Program Partnership's Watershed Model version 5.3 .

Program Partnership (CBP Partnership) for use in the CBP Partnership's Chesapeake Bay Watershed Model. Although the jurisdictions have reported annual progress since the 1990s (U.S. Environmental Protection Agency, 2010, p. 1-4), this reporting has come under additional scrutiny since 2010, when the EPA issued the Chesapeake Bay Total Maximum Daily Load (TMDL) allocations for nitrogen, phosphorus, and sediment (U.S. Environmental Protection Agency, 2010, p. 1-4). The CBP Partnership's Annual Progress Review is used to assess to what extent the Chesapeake Bay watershed jurisdictions are making progress towards meeting their respective set of watershed nutrient and sediment pollutant load allocations. Each jurisdiction reports annual progress (July 1 to June 30) in implementation of conservation practices and treatment technologies for all pollutant source sectors: urban stormwater, wastewater, septic systems, air emissions, forestry, and agriculture. The CBP Partnership is working to ensure that the jurisdictions develop methodologies to reduce potential overcounting of agricultural conservation practices, such as removing previously reported practices that have expired and are no longer achieving the nutrient/sediment reduction benefits described in the model and removing previously reported practices that were on agricultural lands that have 
been converted to another land use. This report focuses on the agricultural conservation practices that are promoted by the USDA.

Concern was expressed by the agricultural community that nutrient and sediment load reductions were not being fully reported by the Chesapeake Bay watershed jurisdictions nor fully credited in the Annual Progress Review, owing to lack of consistent access to USDA conservation practice implementation data and to reporting inconsistencies among the six State jurisdictions. This concern was expressed in multiple Chesapeake Bay Program Partnership meetings, including the Watershed Technical Workgroup (http://www.chesapeakebay.net/groups/group/watershed_technical_workgroup) and the Water-quality Goal Implementation Team (http://www.chesapeakebay.net/groups/group/water_quality_goal_implementation_team).

The U.S. Geological Survey (USGS) took on the task of acquiring, assessing, and evaluating agricultural conservation practice data records for USDA programs and transferring those datasets in aggregated format to State jurisdictional agencies for use in reporting conservation progress to the CBP Partnership. The USGS role was to pilot this work, resolve issues, and set a foundation for future tracking and reporting of USDA practices by the jurisdictions. Accordingly, in 2010, the USGS was established as a USDA 1619 Conservation Cooperator through agreements (appendix B:7, 8) signed with the USDA Natural Resources Conservation Service (NRCS) and the USDA Farm Service Agency (FSA). This status as a cooperator has allowed USGS staff to obtain and handle, in aggregate, Federal farmland conservation data records that are privacy protected as required by Section 1619 of the Food, Conservation, and Energy Act of 2008 (2008 Farm Bill).

The USGS acquired and processed USDA conservation data for the 2012 reporting period (July 1, 2011, to June 30, 2012). The USDA data came from two sources: the FSA and the NRCS. A methodology was developed to request and acquire the USDA conservation practice datasets, clean them to remove internal duplication, aggregate the data to protect farmer privacy, and transfer the data to the jurisdictions. The jurisdictions then chose whether to use these data directly in conservation reporting (DE, PA, WV), or to use existing jurisdictional 1619 agreements to obtain a parallel USDA dataset from local sources (MD, NY, VA). In either case, the six jurisdictions implemented protocols for removing potential duplicate counting of practices that are co-funded by the USDA and the jurisdictions, summarized the practice records by county and practice type, and submitted the aggregated totals to the Annual Progress Review via their respective State National Environmental Information Exchange Network (NEIEN) data transfer nodes. From there, the data were processed through the CBP Partnership's "Scenario Builder" module, where they were translated into CBP Partnership best management practice definitions and credited within the CBP Partnership's Phase 5.3.2. Watershed Model.

A similar tracking, reporting, and assessment will occur in future years as State and Federal governments and nongovernmental organizations continue to work with farmers and conservation districts to reduce the impacts of agriculture on local and Chesapeake Bay water-quality (Chesapeake Bay Program Watershed Technical Workgroup, 2013). The USGS is providing only short-term assistance with obtaining and aggregating USDA conservation practice data, and the USGS-USDA 1619 Conservation Cooperator Agreements are set to expire in 2015. This report discusses the reporting of conservation practices that reduce nutrient and sediment loads from agricultural land. Washington, D.C., is not attributed with agricultural land, so it was not included in this analysis.

\section{Purpose and Scope}

This project was initiated to provide consistency and completeness in reporting of USDA-sponsored agricultural conservation practices among the six Chesapeake Bay watershed jurisdictions with agricultural lands. The USDA engaged the USGS to act as a facilitator and use its expertise to acquire and process conservation data from the NRCS and FSA. As an impartial scientific third party, the USGS was able to play a key role in facilitating communication and data transfer (fig. 2) among the agencies responsible for implementation of Federal conservation programs (NRCS and FSA), the six watershed jurisdictions (DE, MD, NY, PA, VA, and WV), and the organizations responsible for tracking progress towards attaining TMDL conservation goals (EPA and CBP Partnership). Key contacts within each of these agencies were documented (Appendix A).This work was made possible by the signing of 1619 Conservation Cooperator Agreements between the USGS and USDA agencies (FSA and NRCS) that allowed access to Federal conservation data while ensuring the privacy of farmers as mandated under Section 1619 of the 2008 Farm Bill (appendix B:7,8). These USGS-USDA 1619 Conservation Cooperator Agreements will expire in 2015.

The objectives of the project were the following:

- Provide the six watershed jurisdictions with a consistent dataset of USDA financially assisted agricultural conservation practices implemented by NRCS and FSA throughout the Chesapeake Bay watershed jurisdictions, along with consistent definitions for agricultural conservation practices.

- Document the various methods used by the six watershed jurisdictions to obtain agricultural conservation data and address double counting where financial assistance was jointly provided through Federal and State programs. 
- Provide a "crosswalk" document that translates between USDA conservation practice codes and the Chesapeake Bay Program Partnership's approved practice definitions.

- Streamline the overall tracking and reporting process to reduce the workload for the jurisdictions.

- Document and improve existing protocols to support ongoing adaptive management of conservation practice data reporting for Chesapeake Bay watershed agricultural lands and operations.

- The project was designed for USGS to provide short-term leadership in clarifying methods, providing datasets, and resolving issues, to assist the jurisdictions in developing their capacity for full integration of USDA and jurisdictional conservation datasets.

The first step in assisting with the reporting of USDA conservation practices was obtaining a comprehensive dataset. Each conservation record comprises a unique practice implementation on a single farm or field and is associated with a practice code, amount applied, and a considerable variety of detailed information regarding the practice location and characteristics. To determine what data were required, the USGS discussed with each jurisdiction the nature of potential duplication between the jurisdiction's data and USDA data. Once potential areas of duplicate reporting for each jurisdiction were identified, a list of USDA information that would be useful in identifying and eliminating double counting was compiled. This list was added to the list of information that was necessary to achieve accurate reporting of conservation practices and to support linkage to each jurisdiction's National Environmental Information Exchange Network (NEIEN) data interface and the Chesapeake Bay Program Partnership's "Scenario Builder" that is used to account for and credit conservation practices. Separate data requests for conservation practice information (appendix C) were designed and submitted to contact personnel (appendix A) at the FSA and at the NRCS.

Data were obtained in this manner for all farms within the Chesapeake Bay watershed that participate in USDA conservation programs. This method provided a consistent dataset covering all six watershed jurisdictions. The USDA conservation databases are complex, and different data requests can yield somewhat different information, depending on the timing and wording of the request. Use of a single clear and documented protocol to provide data for all jurisdictions led to a streamlined process, further ensuring consistency and transparency among the jurisdictions and ensuring a more complete, comprehensive accounting of implemented conservation practices.

Subsequent data processing steps were designed and documented to ensure consistency, accuracy, and the ability to replicate the data extraction and processing in future years. Much of the data processing included removal of duplicate data. In addition, data aggregation was performed to protect individual farmer privacy to ensure compliance with Section 1619 of the 2008 Farm Bill. The methodology was developed through ongoing conversation with the six watershed jurisdictions, USDA agencies, and the larger Chesapeake Bay Program Partnership.

From this dialogue, jurisdiction-specific methods for incorporating USDA conservation data into the CBP Partnership's Annual Progress Review process were developed and documented. Three of the jurisdictions (PA, DE, and WV) chose to use the USGS-provided dataset for reporting USDA conservation practices to the Annual Progress Review. The other three jurisdictions (MD, NY, and VA) chose to use locally sourced USDA data obtained via their jurisdictional USDA 1619 Conservation Cooperator Agreements (appendix B:1-6) but to employ the USGS-provided data to validate the jurisdictional datasets that they used to track both Federal and State conservation practices.

Tools that the USGS has provided to the six Chesapeake Bay watershed jurisdictions to facilitate their reporting of USDA agricultural conservation data include the following:

- A consistent and complete database of FSA and NRCS conservation practices implemented within the Chesapeake Bay watershed, in both unaggregated and aggregated format (delivered to the jurisdictions).

- A listing of useful information that can be obtained from the USDA conservation databases, including a list of available data attributes (appendix D).

- A crosswalk between USDA practice codes and conservation practice categories used by the CBP Partnership (appendix E).

- A USDA-approved methodology for data aggregation to protect confidential farmer information (appendix B: 9).

- Documentation of State-specific methods used in removing duplicate information records for practices that received financial assistance by both a jurisdiction and the USDA (in "Protocols for Avoiding Double Counting," below).

- A review of existing language for 1619 Conservation Cooperator Agreements along with FSA-recommended language suitable to obtain consistent and comprehensive access to USDA conservation data throughout the Chesapeake Bay jurisdictions (appendix B). 
The methods employed in 2012 are documented here and shared with each watershed jurisdiction so that they may report USDA conservation data more easily, accurately, and completely in future years. The USGS is providing only short-term assistance with obtaining and aggregating USDA conservation practice data, and the USGS-USDA 1619 Conservation Cooperator Agreements are set to expire in 2015.

It should be emphasized that the primary purpose of gaining complete access to Federal, State, and private agricultural conservation implementation data is to give the jurisdictions a greater capacity for analysis and understanding of agricultural conservation practice implementation across the landscape, to support the adaptive management and targeting of conservation programs, fully credit producers for their implemented conservation practices, and promote success in attaining water-quality goals. The reporting aspect is also important because it will assist the jurisdictions in coordinating the development of knowledge to understand and document progress toward water-quality goals.

\section{Data Confidentiality: USDA 1619 Conservation Cooperator Agreements}

The conservation assistance that is provided to farmers by the USDA is authorized under the 2008 Farm Bill, and Section 1619 of that bill (appendix B: 1-8) states that, "USDA, or any contractor or cooperator of USDA, shall not disclose information provided by an agricultural producer or owner of agricultural land concerning the agricultural operation, farming or conservation practices, or the land itself, in order to participate in the programs of the Department ..," except to agencies and individuals that have been established as USDA 1619 Conservation Cooperators. This means that information that is used by a farmer to enroll in Federal agricultural programs is defined as confidential between the farmer and the Federal Government.

Organizations can be established as 1619 Conservation Cooperators if they agree to maintain data confidentiality and if their use of the data provides technical or financial assistance to USDA conservation programs. Signing a 1619 Conservation Cooperator Agreement provides the cooperator with confidential access to the USDA's datasets of conservation practice information. The data can be released to the public if they are aggregated so that farmer privacy is protected, as discussed below. These 1619 aggregation requirements are regularly followed by USDA agencies such as the National Agricultural Statistics Service when they are publishing county statistics. Farmers can also release their site-specific data on an individual basis.

The 1619 Conservation Cooperator Agreements can be authorized by State and regional officials of the NRCS or FSA. Ultimately, responsibility for enforcing Section 1619 of the 2008 Farm Bill lies with the FSA, and at the national level the FSA Privacy Officer (John Underwood, appendix A) has authority to review and approve 1619 Conservation Cooperator Agreements for both the FSA and NRCS, and to sign for the FSA. Because the NRCS collaborates closely with is sister agency in delivering conservation services, and NRCS planners have access to the FSA Common Land Unit field boundary dataset, the NRCS agreements tend to specify that they apply to both NRCS and FSA conservation information. Therefore, jurisdictional agencies do not necessarily have to sign agreements with the FSA to gain access to FSA-managed conservation datasets, which include geospatial Common Land Unit (CLU) field boundaries as well as Conservation Reserve Program (CRP) and Conservation Reserve Enhancement Program (CREP) practices. The most comprehensive authorization option is to obtain signatures from both NRCS and FSA officials (see suggested language in appendix B:10). The agreements have start and end dates in most cases. The presence of an end date depends on the preference of the USDA signing official. Agreements may be amended by mutual agreement of all parties with signatory authority.

\section{Section 1619 Agreements: Existing Language in the Jurisdictions}

Four jurisdictions currently have established USDA 1619 Conservation Cooperator Agreements between the NRCS and one or more of their State conservation agencies (MD, NY, VA, and WV). The remaining jurisdictions (DE and PA) have not yet established conservation cooperator status for any of their conservation agencies. The agreements state that "Those individuals or organizations (governmental or nongovernmental) that assist the NRCS with providing conservation related services are known as NRCS Conservation Cooperators."

The following State agencies have established 1619 Conservation Cooperator Agreements with the USDA (table 1, appendix B:1-5) for the purpose of providing privacy-protected access to USDA conservation data:

- Maryland: Maryland Department of Agriculture (MDA)

- New York: Upper Susquehanna Coalition (USC)

- Virginia: Virginia Department of Conservation and Recreation (VA-DCR)

- West Virginia: West Virginia Department of Agriculture (WVDA) 


\section{- West Virginia: West Virginia Conservation Agency (WVCA)}

These existing jurisdictional 1619 agreements (appendix B:1-5) are fairly consistent, but they differ in the wording of several key factors as described below. As a result, there are some important differences in the level of data access provided by the agreements, with some jurisdictions including a broader array of programs and practices than others (table 1). The broadest language for each of the key factors, which will ensure full access to all USDA conservation practice data, is printed below in italics. It should be mentioned that, despite differences in language, the effective interpretation of the agreements by the NRCS has been fairly broad and uniform, and was sufficient to provide full access to USDA data by the signatory jurisdictions in 2012.

Purpose: The agreements with Maryland, New York, and West Virginia all begin by stating that each of the State signatory agencies "assists NRCS in the delivery of conservation-related services (for example: services that sustain agricultural productivity, improve environmental quality, reduce soil erosion, enhance water supplies, improve water-quality, increase wildife habitat, and reduce damage caused by floods and other natural disasters) or with monitoring, assessing, or evaluating of conservation benefits from USDA conservation programs. "In Virginia, this language is reduced to the simplest NRCS Attachment C language (see appendix B:3): "provide technical and/or financial assistance for USDA conservation programs."

Limits: The simplest NRCS Attachment C language, which is used by New York and West Virginia, establishes that data access is limited to information necessary to "provide conservation related services." The Maryland agreement expands the language regarding data access to include information required to "provide conservation related services and perform monitoring, assessing, or evaluating of conservation benefits." In Virginia, data access is limited to information "necessary for the delivery of technical and/or financial assistance for conservation programs," and goes on to list six authorized technical assistance activities, including "compliance and status reviews." End dates of the various agreements are listed in table 1.

Aggregation: In all four cases-MD, NY, VA, and WV - the 1619 agreements establish that disclosure of protected information is allowed if "the information has been transformed to statistical aggregate form without naming any owner, operator, producer, or data gathering site." In most jurisdictional agreements this language is stated explicitly, whereas for Virginia (see appendix B:3) it is established via reference to "Section 1619 Attachment 1." The agreements state that the 1619 Conservation Cooperators must consult with the NRCS as to whether the data are appropriately aggregated prior to releasing information.

Data: The existing 1619 agreements do not limit the types of data that are being made available but do list example types of "prohibited information," including all attributes for Common Land Units (CLUs) in the USDA's Geospatial Information System. The existing agreements are interpreted by the FSA Privacy Officer John Underwood (appendix A) as providing access to NRCS practice data along with CLU field boundaries and FSA CRP and CREP practice data. The broadest language currently recommended by the FSA Privacy Officer would read: "The protected data types approved for disclosure are limited to: Fully attributed conservation practice tabular numerical and text data and geospatial information depicting NRCS and FSA conservation practices and Common Land Unit (CLU) data for the State of \{state name\}. The geospatial information provided will not include any producer/owner Personally Identifiable Information (PII)."

Privacy: The agreements with Maryland and West Virginia explicitly state that Section 1619 supersedes State "sunshine laws," "open records acts," and "the Freedom of Information Act." Jurisdictions with laws stating that State acts supersede the Federal privacy regulations are not permitted to sign 1619 Conservation Cooperator Agreements.

Access: Typically, the agreement language states that Conservation Cooperators may obtain USDA conservation data from the NRCS or directly from farmers. The USGS agreements (see below) also state that data can be obtained from other 1619 Conservation Cooperators. However, the horizontal data transfer among States is not a desired functionality within Statespecific 1619 data-sharing agreements. In Virginia, the 1619 agreement (appendix B:3) was signed by a specific individual within the Department of Conservation and Recreation who had responsibility for the Annual Progress Review, and data access was therefore limited to that person. This was interpreted by the FSA Privacy Officer to also include his successor in that job posting. Because the 1619 agreements can be amended through mutual consent, additional individuals within an agency may be added to such limited agreements upon approval by USDA.

\section{USGS Section 1619 Agreements for the Chesapeake Bay Watershed}

The USGS was established as a USDA 1619 Conservation Cooperator in 2010, under separate agreements with the FSA ("Cooperative Agreement," appendix B:6) and the NRCS ("Cooperative Interagency Agreement," appendix B:7). These agreements contain particular language developed to support the broad USGS objective of facilitating jurisdictional access to agricultural conservation practice data for the Chesapeake Bay watershed.

Purpose: The agreements state that the USGS is "providing technical or financial assistance under a USDA program that concerns an agricultural operation, agricultural land, farming practice, or conservation practice."

Limits: The USGS is authorized to use the Federal conservation data in aggregate "to provide technical assistance, in the form of monitoring, assessment, and evaluation, of USDA Farm Bill Programs... by analyzing the impact of farming practices on water-quality in the Chesapeake Bay watershed." 
Aggregation: The 1619 agreements authorize the USGS to "release aggregated statistical information to Chesapeake Bay Program partner organizations and the public following review and approval by USDA of data aggregation procedures to ensure compliance with Section 1619." This wording allowed the USDA to approve the overall aggregation protocol rather than each aggregated data product (for example, conservation practice data aggregated to the county scale, throughout the Chesapeake Bay watershed). A data-handling procedure was developed by the USGS and approved by the USDA (appendix B:8), establishing that aggregate data for each particular conservation practice could be released to the public if five or more farm owner/operators were participating in a particular conservation practice within the aggregated area.

Access: Through its 1619 agreements, the USGS was authorized to receive USDA data from the FSA, NRCS, individual farmers, or from other 1619 Conservation Cooperators. Through additional and explicit approval (appendix B:9) from the FSA Privacy Officer, the USGS was also authorized to transmit USDA data to specific 1619 Conservation Cooperators (the jurisdictional agencies with 1619 agreements in place).

Although some labor was involved in reconciling the wording of the various 1619 agreements and in receiving permissions to share data between the USGS and the State agencies, the four jurisdictional agencies with 1619 Conservation Cooperator Agreements in place (MD, NY, VA, and WV) were ultimately given access to the unaggregated (site-specific) USDA agricultural conservation practice data that were compiled by the USGS in 2012. In the case of the Virginia Department of Conservation and Recreation (VA-DCR), owing to the wording of its 1619 agreement, this access was limited to two key individuals (Bill Keeling and Lawrence Fender, appendix A). 
Table 1. Status of 1619 Conservation Cooperator Agreements for each Chesapeake Bay jurisdiction. These agreements facilitate access to USDA agricultural conservation data on a privacy protected basis. See page vii in text for agency abbreviations. Two jurisdictions (Delaware and Pennsylvania) do not currently have 1619 agreements in place.

\begin{tabular}{|c|c|c|c|c|c|c|}
\hline Jurisdiction & Agency & Purpose & Limits & Data covered & Start date & End date \\
\hline Maryland & MDA & $\begin{array}{l}\text { Assist NRCS in } \\
\text { the delivery of } \\
\text { conservation-related } \\
\text { services. }\end{array}$ & $\begin{array}{l}\text { Provide conservation- } \\
\text { related services; } \\
\text { monitor, assess, evaluate } \\
\text { conservation benefits. }\end{array}$ & $\begin{array}{l}\text { Not limited; lists } \\
\text { specific data that } \\
\text { may be viewed. }\end{array}$ & $10 / 27 / 2009$ & None \\
\hline New York & USC & $\begin{array}{l}\text { Assist NRCS in } \\
\text { the delivery of } \\
\text { conservation-related } \\
\text { services. }\end{array}$ & $\begin{array}{l}\text { Provide conservation } \\
\text { related services. }\end{array}$ & $\begin{array}{l}\text { Not limited; lists } \\
\text { specific data that } \\
\text { may be viewed. }\end{array}$ & $3 / 3 / 2011$ & None \\
\hline Virginia & DCR & $\begin{array}{l}\text { Provide techni- } \\
\text { cal assistance for } \\
\text { USDA conservation } \\
\text { programs. }\end{array}$ & $\begin{array}{l}\text { Lists authorized activities } \\
\text { including "compliance } \\
\text { and status reviews." }\end{array}$ & $\begin{array}{l}\text { Not limited; lists } \\
\text { specific data that } \\
\text { may be viewed. }\end{array}$ & $12 / 4 / 2009$ & None \\
\hline West Virginia & DA & $\begin{array}{l}\text { Assist NRCS in } \\
\text { the delivery of } \\
\text { conservation-related } \\
\text { services. }\end{array}$ & $\begin{array}{l}\text { Provide conservation- } \\
\text { related services. }\end{array}$ & $\begin{array}{l}\text { Not limited; lists } \\
\text { specific data that } \\
\text { may be viewed. }\end{array}$ & $4 / 7 / 2012$ & None \\
\hline West Virginia & $\mathrm{CA}$ & $\begin{array}{l}\text { Collect data to } \\
\text { document and verify } \\
\text { practices. }\end{array}$ & $\begin{array}{l}\text { WV animal operations in } \\
\text { the Potomac Basin. }\end{array}$ & $\begin{array}{l}\text { Animal waste } \\
\text { management and } \\
\text { mortality disposal } \\
\text { systems. }\end{array}$ & $2 / 21 / 2012$ & $3 / 1 / 2013$ \\
\hline Federal & USGS & $\begin{array}{l}\text { Provide technical as- } \\
\text { sistance for a USDA } \\
\text { program. }\end{array}$ & $\begin{array}{l}\text { Monitoring, assessment, } \\
\text { and evaluation; impact } \\
\text { of farming practices } \\
\text { on water-quality in } \\
\text { the Chesapeake Bay } \\
\text { watershed. }\end{array}$ & $\begin{array}{l}\text { CRP and CREP, field } \\
\text { boundaries, for States } \\
\text { in Chesapeake Bay. }\end{array}$ & $8 / 2 / 2010$ & $9 / 30 / 2015$ \\
\hline Federal & USGS & $\begin{array}{l}\text { Provide technical } \\
\text { assistance for a } \\
\text { USDA program. }\end{array}$ & $\begin{array}{l}\text { Monitoring, assessment, } \\
\text { and evaluation; impact } \\
\text { of farming practices } \\
\text { on water-quality in the } \\
\text { Chesapeake Bay water- } \\
\text { shed. }\end{array}$ & Farm Bill programs. & $11 / 20 / 2010$ & $9 / 30 / 2015$ \\
\hline
\end{tabular}

\section{Data Access for the Chesapeake Bay Program Partnership's Annual Progress Review}

Each of the jurisdictions has identified a key State agency with responsibility for submitting aggregated agricultural conservation practice data to the CBP Partnership's Annual Progress Review, through their respective State's NEIEN data transfer node (table 2). These agencies work in partnership with additional jurisdictional and Federal agencies to collect and compile the necessary conservation practice implementation data, often funded in the process by the EPA's Chesapeake Bay Regulatory and Accountability Program Grants (CBRAP) to the jurisdictions.

In 2012, the USGS provided three of the Chesapeake Bay jurisdictions (DE, PA, and WV) with a database of USDA conservation practice implementation records that were aggregated by county, suitable for public release. This aggregation meets the 1619 requirements that protect agricultural producer identity. Specifically, practice implementation is only reported in aggregate form if five or more producers implemented the practice in a particular geographic area. Those data were integrated with the jurisdictional records of State-funded practices and submitted to the CBP Partnership's Annual Progress Review by each State through the respective State NEIEN node. The remaining three jurisdictions (MD, NY, and VA) had 1619 Conservation Cooperator Agreements in place and chose to obtain USDA conservation data directly from the USDA and jurisdictional databases, without using the USGS-provided dataset. 


\section{Delaware}

In Delaware, the Department of Natural Resources and Environmental Control (DE-DNREC) has full responsibility for reporting practices to the EPA for use in the CBP Partnership's Annual Progress Review, including data submission through Delaware's State NEIEN node. Because Delaware does not have a 1619 data sharing agreement in place, in 2012 they relied upon the USGS to provide an aggregated dataset of USDA conservation practices, which was then integrated with jurisdictional records of State financially assisted agricultural conservation practices and urban stormwater, onsite treatment systems, and wastewater practices. The USDA data used in previous years were acquired from the Delaware State NRCS Office in an aggregated format.

\section{Maryland}

In Maryland, the Department of Agriculture (MDA) has been established as a 1619 Conservation Cooperator with the NRCS (appendix B:1). Supported by this jurisdictional 1619 data-sharing agreement, Maryland has developed an integrated "Conservation Tracker" database that is used within each Conservation District office to document Federal, State, and nongovernmental organizations' financial assistance and conservation practices installed without Federal or State financial assistance. This database has made it comparatively easy for Maryland to eliminate double counting and accurately report conservation practice implementation. The MDA compiles and aggregates the Conservation Tracker dataset; joins the resulting data with additional jurisdictional databases documenting cover crops, manure transport, and nutrient management; and then transmits the aggregated data to the Maryland Department of the Environment (MDE), which is the lead Maryland agency for operation and maintenance of Maryland's State NEIEN node.

\section{New York}

In New York, the Upper Susquehanna Coalition (USC) has been established as a 1619 Conservation Cooperator with the NRCS (appendix B:2). The USC is made up of various collaborators within the Soil and Water Conservation Districts serving the area of New York in the Chesapeake Bay watershed and currently has full responsibility for reporting practices for the CBP Partnership's Annual Progress Review, including data submission through the New York's State NEIEN node. Because the portion of New York that falls within the Chesapeake Bay watershed is relatively small (comprising 16 Soil and Water Conservation Districts), the USC has established a method of meeting with each of its member Soil and Water Conservation Districts to obtain annual conservation implementation data. During this process, the USC also collects information on practice implementation from partners such as the NRCS and Cornell Cooperative Extension.

The USC's Soil and Water Conservation Districts organize conservation data within the New York's Agricultural Environmental Management (NY-AEM) framework that they use to track both State and federally financed conservation practices. The NY-AEM is part of the overall Agricultural Environmental Management umbrella, which, by State law, partners the New York State (NYS) Department of Agriculture and Markets, the NYS Soil and Water Conservation Committee, and the Soil and Water Conservation Districts in a multifaceted program for conservation on farms. Within this framework the USC has developed an online tool to record and report State and federally financed conservation practices. Although the NY-AEM online tool was not used for progress reporting in 2012, it has the potential to make it comparatively easy for the USC to eliminate double counting and accurately and consistently report conservation practice implementation for the CBP Partnership's Annual Progress Review. In 2013, responsibility for operation and maintenance of New York's State NEIEN node (in terms of submission of annual Chesapeake Bay watershed agricultural conservation practice data) is in the process of being transferred from the USC to the NYS Department of Environmental Conservation (NY-DEC).

\section{Pennsylvania}

In Pennsylvania, the Department of Environmental Protection (PA-DEP) has responsibility for reporting practices for the CBP Partnership's Annual Progress Review, including data submission through Pennsylvania's State NEIEN node. Because this agency does not have a 1619 agreement in place, in 2012 Pennsylvania relied upon the USGS to provide an aggregated dataset of USDA conservation practices, which was then integrated with the jurisdictional spreadsheet of State-funded practices.

\section{Virginia}

In Virginia, the Department of Conservation and Recreation (VA-DCR) has been established as a 1619 Conservation Cooperator with the NRCS (appendix B:3) and has full responsibility for reporting practices, including data submission to the 
CBP Partnership's Annual Progress Review. The Virginia 1619 agreement limits data access to the specific individual within VA-DCR that is responsible for the Annual Progress Review. Because the VA-DCR does not have an integrated Federal-State data tracking system, this person obtains USDA conservation practice data by requesting them from the Virginia State NRCS office, where the data are compiled by querying the NRCS Integrated Data for Enterprise Analysis (IDEA) database. This dataset is then integrated with the jurisdictional database of State-funded practices and the data are aggregated prior to submission to the Annual Progress Review by using node client software for reporting extensible markup language files. In 2013, responsibility for the Annual Progress Review data submission is shifting from the VA-DCR to the Virginia Department of Environmental Quality (VA-DEQ), and there is currently no 1619 agreement in place for that agency.

\section{West Virginia}

In West Virginia, the Department of Agriculture (WVDA) has been established as a 1619 Conservation Cooperator with the NRCS (appendix B:4) but cannot share unaggregated conservation practice information with the Department of Environmental Protection (WVDEP), which is the agency responsible for submitting data through West Virginia's State NEIEN node. The West Virginia Conservation Agency (WVCA) was also established as a cooperator with the NRCS under a memorandum of understanding covering only animal waste disposal and poultry mortality disposal in the Potomac Basin (appendix B:5). That agreement was recently renewed. Although West Virginia is a 1619 Conservation Cooperator (via the WVDA and WVCA), NRCS staffing and priorities led the WVDEP to rely upon the USGS to provide an aggregated dataset of 2012 USDA conservation practices, which was then integrated with the jurisdictional database of State-funded practices and submitted through West Virginia's State NEIEN node.

Interestingly, the two jurisdictions with the most comprehensive 1619 agreements (MD and NY) have established jurisdictional integrated databases of Federal and State-sponsored agricultural conservation practices. This allows these States to directly track cost-shared conservation practices regardless of the source of financial assistance (State, Federal, or private) and address the removal of double counting in a relatively straightforward manner. It also has greatly simplified their annual reporting to the CBP Partnership's Annual Progress Review. These results imply that Virginia might benefit from establishing a combined jurisdictional database of Federal and State practices. Currently, Virginia has a labor-intensive data submission process, owing to the State's use of record-by-record comparison for removal of double-counted practices, as described below.

\section{Establishing new 1619 Conservation Cooperator Agreements}

The following jurisdictional agencies with responsibility for conservation data reporting do not currently have 1619 Conservation Cooperator Agreements in place and must rely upon obtaining aggregated conservation data from their collaborators:

- Delaware Department of Natural Resources and Environmental Control (DE-DNREC).--Receives aggregated conservation practice data from the conservation districts and the USGS, and submits the data to the CBP Partnership's Annual Progress Review through the Delaware NEIEN node.

- Maryland Department of the Environment (MDE).-Receives aggregated conservation practice data from Maryland Department of Agriculture and submits the data to the CBP Partnership's Annual Progress Review through the Maryland State NEIEN node.

- New York Department of Environmental Conservation (NY-DEC).-Will be assuming responsibility for submission of data to the New York NEIEN node, working in partnership with the Upper Susquehanna Coalition.

- Pennsylvania Department of Environmental Protection (PA-DEP).--Receives aggregated conservation data from conservation program leads, conservation districts, and the USGS, and submits the data for the CBP Partnership's Annual Progress Review through Pennsylvania's State NEIEN node. The Department of Environmental Protection is the Pennsylvania State agency with direct responsibilities for planning, funding, delivery, reporting, and submission of conservation-practice data. In addition to providing conservation services, it is also a regulatory agency.

- Virginia Department of Environmental Quality (VA-DEQ). - Is assuming responsibility for the Annual Progress Review from the VA-DCR, and a number of conservation programs are also in the process of being transitioned from the VADCR to VA-DEQ following recently enacted legislation. The implications for 1619 data access in Virginia are currently unclear, pending final transition of programmatic responsibilities between the two agencies.

- West Virginia Department of Environmental Protection (WVDEP).--Receives aggregated conservation data from the West Virginia Department of Agriculture, the West Virginia Conservation Agency, and the USGS, and submits the data for the CBP Partnership's Annual Progress Review through West Virginia's State NEIEN node. 
Several additional agencies that are directly involved in conservation planning, funding, delivery, and reporting of conservation-practice data also do not have 1619 data-sharing agreements in place:

- Delaware Department of Agriculture (DE-DA). - Currently provides aggregated jurisdictional records to the DE-DNREC for use in reporting to the CBP Partnership's Annual Progress Review.

- Delaware Forest Service (DE-FS).-_Promotes forestry conservation practices with USDA financial assistance.

- Pennsylvania Department of Agriculture (PA-DA).-Promotes conservation practices in collaboration with the USDA and PA-DEP.

- West Virginia Conservation Agency (WVCA).- Has established a 1619 agreement covering animal waste and mortality data only. The agency currently provides aggregated conservation data to the WVDEP.

In support of the NRCS Chesapeake Bay Watershed Initiative (CBWI), the NRCS has encouraged jurisdictional conservation agencies that do not have 1619 agreements in place to request to establish one (Rich Sims, appendix A). Each of the jurisdictional agencies listed in table 2 has been vetted and approved by the FSA Privacy Officer, in collaboration with the NRCS regional conservationists, as eligible for USDA 1619 Conservation Cooperator status because the agency supplies conservation technical assistance to NRCS programs under the definitions established by the NRCS Chesapeake Bay Watershed Initiative (http://www.nrcs.usda.gov/wps/portal/nrcs/detailfull/national/programs/farmbill/?cid=stelprdb1047323).

This list does contain State regulatory agencies including the DE-DNREC, MDE, NY-DEC, PA-DEP, VA-DEQ, and WV-DEP, although most of these agencies also have direct responsibility for planning, funding, and implementation of conservation practices and provide conservation technical assistance to farmers. Several of the NRCS State Conservationists in the Chesapeake Bay have stated that 1619 agreements will not be provided to regulatory agencies. However, it is possible to word 1619 agreements to specifically limit access to the few key individuals within those agencies who are responsible for conservation data reporting (see suggested language in appendix B:10). For example, at the USGS only employees who have signed an internal 1619 data-handling agreement with specific data-use objectives (appendix B:8) are allowed access to the protected conservation dataset. A similar strategy could be used by the jurisdictional agencies to maintain a firewall between regulation and conservation implementation/reporting while still allowing critical staff access to the USDA dataset to assist in jurisdictional conservation reporting and management.

Table 2. State jurisdictional agencies that have been approved by the USDA for participation in 1619 data-sharing agreements to support the objectives of the NRCS Chesapeake Bay Watershed Initiative and increase the capacity for consistent, integrated analysis and reporting of conservation practice implementation data for the Chesapeake Bay watershed. See page vii of text for agency abbreviations.

\begin{tabular}{llll}
\hline \multicolumn{1}{c}{ Jurisdiction } & \multicolumn{1}{c}{ Agency } & \multicolumn{1}{c}{ Role } & 1619 agreement in place? \\
\hline Delaware & DE-DNREC & Responsible for NEIEN submission. & No \\
& DE-DA & Provides conservation services. & No \\
& DE-FS & Provides conservation services. & No \\
Maryland & MDA & Provides conservation services. & Yes \\
& MDE & Responsible for NEIEN submission. & No \\
New York & USC & Provides conservation services.* & Yes \\
& NY-DEC & Responsible for 2013 NEIEN submission. & No \\
Pennsylvania & PA-DEP & Responsible for NEIEN submission.** & No \\
& PA-DA & Provides conservation services. & No \\
Virginia & VA-DCR & Provides conservation services. & Yes \\
& VA-DEQ & Responsible for NEIEN submission. & No \\
\hline
\end{tabular}

The development of a multi-organizational 1619 Conservation Cooperator Agreement to cover all relevant agencies was proposed to the CBP Partnership at the September 12, 2012, Best Management Practice (BMP) Verification Committee meeting (http://www.chesapeakebay.net/calendar/event/18557/). The proposal was well received by both the jurisdictions and other members of the BMP Verification Committee, and steps were taken to further explore the creation of a multi-organizational agreement as is evidenced in the minutes at the aforementioned meeting Web site. 
A multi-organizational 1619 Conservation Cooperator Agreement could have several benefits, including the following:

- Simplification for USDA, USGS, and jurisdictional staff (one data request rather than many)

- Consistency of data (supporting uniform reporting throughout the Chesapeake Bay watershed)

- Increasing access to unaggregated, farm-specific data (to increase capacity for analysis of conservation implementation to support adaptive management of conservation programs)

However, on March 13, 2013 the CBP's Partnership's BMP Verification Committee decided “ ...not to pursue a single sixstate 1619 agreement, but instead seeking all six states signing their own individual 1619 agreements with the NRCS and FSA. The bottom line objective remains the same: ensuring that all six states have full access only to all financially-assisted Federal conservation practice data to be used to eliminate any double counting, support effective conservation program implementation, and fully credit their producers for their nutrient and sediment load reduction implementation actions. The data are only released in aggregate form to protect the confidentiality of agricultural producers. The Committee agreed to recommend to the Partnership that the six states, the USDA, and other appropriate partners sign a cover page referencing the attached six state-specific 1619 agreements collectively ensure all six states have full access to Federal financially assisted practice data."

Establishing a comprehensive set of 1619 agreements for all relevant jurisdictional agencies could help to solve many technical details involved in obtaining accurate reporting of Federal and State progress in implementing agricultural conservation practices. The development of 1619 agreements between the USDA and the agencies listed in table 2 could greatly increase the capacity for integrated analysis and reporting of agricultural conservation implementation. Use of consistent, comprehensive language within the agreements, such as is documented in appendix B:10, could support the use of a single data request to obtain USDA data for all jurisdictions in the Chesapeake Bay watershed, which could streamline efforts and promote equity in conservation data reporting across the Chesapeake Bay watershed. This uniform dataset could be tailored to formats that integrate effectively within each State's respective conservation tracking and reporting system.

However it is achieved, whether agency-by-agency or through multi-organizational agreements, adopting consistent and thorough language for 1619 Conservation Cooperator Agreements for all relevant jurisdictional conservation agencies could greatly assist in meeting the objective of increasing capacity for analysis and understanding of implementation in support of adaptive management of conservation programs, as well as establishing consistency and accuracy among the jurisdictions in reporting of USDA conservation data for Chesapeake Bay agricultural lands.

In the absence of 1619 Conservation Cooperator status, the jurisdictional agencies can work to develop more effective, consistent, and well-documented methods of obtaining aggregated conservation data from collaborating agencies that are 1619 Conservation Cooperators, and smoothly integrating those data with jurisdictional datasets.

\section{Data Collection and Processing}

In 2012, the USGS obtained USDA conservation data for NRCS and FSA programs and provided these data to the six Chesapeake Bay jurisdictions to support their reporting of conservation practice implementation to the CBP Partnership's 2012 Annual Progress Review. The methods used are detailed in this report. The data collection and processing steps required of the USGS included

- obtaining the data from USDA agencies (NRCS, FSA),

- cleaning the USDA dataset to remove internal duplication,

- aggregation of data to ensure producer privacy,

- establishing a "crosswalk" document to translate between USDA and Chesapeake Bay Program Partnership approved practice definitions,

- transmittal of the data to each jurisdiction for use in the reporting process, and

- communication with each jurisdiction to establish and document solutions for avoiding double counting as the datasets are integrated.

The jurisdictions integrated USDA data with their State reporting systems, removed duplicate records, and delivered aggregated summaries of 2012 conservation practice implementation (new practices implemented between July 1, 2011, and June 30, 2012) to the CBP Partnership's Annual Progress Review. The jurisdictions report conservation data from all nutrient and sediment pollutant source sectors. For agriculture, depending on their preference, the jurisdictions can choose to report USDA 
conservation practices either from the data provided by the USGS or from the jurisdiction's own data sources (site-specific data obtained from State NRCS offices under jurisdictional 1619 agreements, or aggregated totals received from the collaborating jurisdictional agencies that are responsible for practice implementation). The deadline for reporting 2012 data to the Annual Progress Review was December 31. However, the deadline for 2013 is December 1.

\section{Implementing Agricultural Conservation Practices}

A farmer may have a variety of reasons for choosing to adopt agricultural conservation practices, including regulation (for example, compliance with management requirements for highly erodible land or concentrated animal feeding operations), incentives (financial assistance for various practices), or stewardship. The typical flow of business begins with a field technical staff person working with a farmer to design and implement recommended conservation practices. The USDA Service Center offices that are found in nearly every county of the Nation are typically staffed by a mixture of employees working for the NRCS,

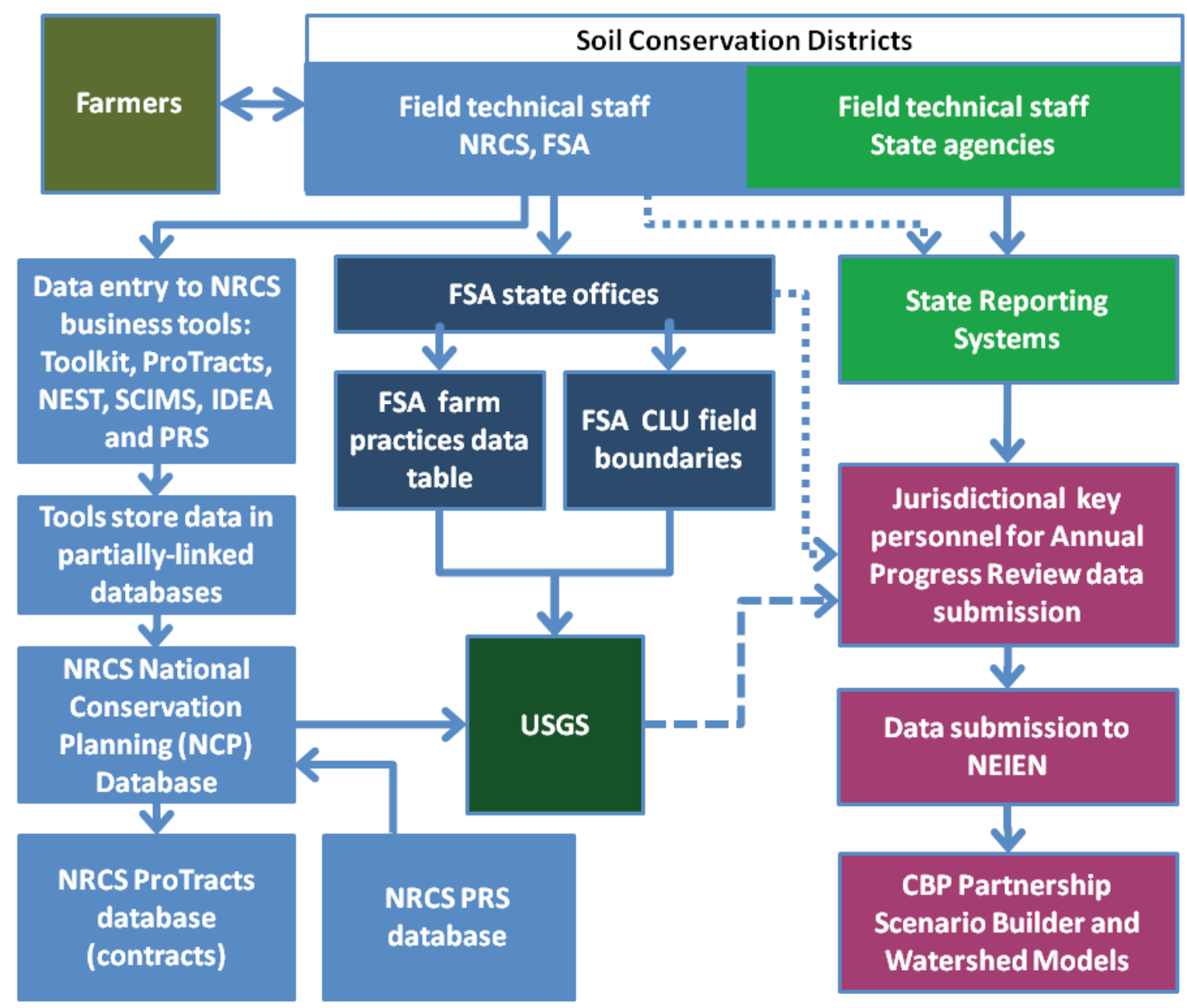

Key:

" " " $\rightarrow$ Direct data transfer from USDA for jurisdictions with 1619 agreements (MD, NY, VA)

$=-\Rightarrow$ Aggregated data transfer from USGS (DE, PA, WV)

Figure 2. Flow diagram of USDA conservation data collection and reporting strategies. See page vii of text for abbreviations. 
county conservation districts, and State conservation agencies. Additional conservation support can be provided by the FSA, university extension, private agricultural technical service providers, and nongovernmental organizations.

Once a practice or set of practices is chosen by the farmer, available funding sources may be determined. In some jurisdictions, and for some practices, financial assistance may be available only from USDA programs. Other jurisdictions may provide financial assistance for specific practices from State agencies, and private funds are sometimes available from sponsored programs. Additionally, farmers may cover a substantial portion of the cost. Funding availability is practice specific, and some practices are considered higher priority in certain locations and in certain years.

Conservation practices can be generally separated into two classes: structural practices, in which engineered improvements such as improved barnyards, stream crossings, manure storage structures, and filtration swales are expected to last for several to many years; and management practices such as cover crops and nutrient management, which are applied one growing season at a time. The NRCS will subsidize the management practices for 1 to 3 years, after which it is hoped that farmers will continue the practices on their own. Indeed, for most management practices, it is the NRCS perspective that funding is designed to help a farmer through the adoption phase for best management practices, after which the farmer will be prepared to continue the practice using only on-farm resources. The FSA conservation practices (funded under the CRP and the CREP) generally cover fencing, vegetative cover (grass, shrubs and trees), and set-asides of critical natural habitat and near-stream areas, with contracts lasting 10 years or more.

Once a farm owner/operator commits to implementing a conservation practice, funding is identified, the farmer is determined to be eligible for the program, then a contract is signed and the practice is implemented and inspected according to established guidelines. Depending on the source of funds, the pertinent information (farmer, contract, location, and practice details) is recorded into one or more jurisdictional and (or) USDA databases by an employee of the conservation district, the NRCS, and (or) FSA.

\section{Documenting Agricultural Conservation Practices}

For the FSA, conservation data records for new Conservation Reserve Program (CRP) and Conservation Reserve Enhancement Program (CREP) practices are collected on a monthly basis from county FSA offices, rolled up through FSA State coordinators, and reported to the Aerial Photography Field Office (http://www.fsa.usda.gov/FSA/apfoapp? area=apfohome\&subject $=$ la nding\&topic=landing). The records contain a practice code, applied date, and various implementation details and metrics.

For the NRCS, conservation data records are entered into integrated agency business tools and relational databases (fig. 2) by NRCS field office staff. The Conservation Toolkit planning information is stored in the National Conservation Planning (NCP) database, which contains progress/performance information for all NRCS conservation programs but does not include financial information. The NRCS customer data originate with the USDA Service Center Information Management System (SCIMS) data. Easement boundaries are stored in the National Easements Staging Tool (NEST). The NRCS ProTracts system is the repository for the financial contract information for the Environmental Quality Incentives Program (EQIP), Agricultural Water Enhancement Program (AWEP), Agricultural Management Assistance Program (AMAP), Wildlife Habitat Incentive Program (WHIP), and Conservation Stewardship Programs (CSP). Progress data are recorded primarily in the Performance Results System (PRS) database. The ProTracts data and PRS data are also linked to the NCP database to track common data. References describing several of these complex database systems can be obtained at

www.nrcs.usda.gov/Internet/FSE_DOCUMENTS/stelprdb1045976.pdf.

For the purposes of this project, the data stored in the NCP database were most appropriate. This project worked with tabular data that were queried from the NCP database by David Butler (appendix A), at the NRCS Information Technology Center, in Fort Collins, Colorado. A similar (but not identical) dataset can also be obtained by using the Integrated Data for Enterprise Analysis (IDEA) interface that combines data from multiple NRCS software systems.

The jurisdictions also keep independent conservation tracking systems. Some jurisdictions, such as Maryland (Conservation Tracker database) and New York (Agricultural Environmental Management database), require all NRCS and FSA financially assisted practices to be entered into jurisdictional data tracking systems by Service Center Office staff, along with State-funded practices and practices for which the Service Center Office has provided conservation technical assistance without financial assistance. Other jurisdictions (DE, PA, VA, and WV) do not have statewide combined reporting and tracking systems. Most of these jurisdictions maintain conservation data tracking systems that partially overlap with USDA databases, depending on the particular practice. Discussion of processes employed to remove duplicate data follows in later sections.

\section{Obtaining USDA Agricultural Conservation Practice Data}

In 2010, 1619 Conservation Cooperator Agreements (appendix B:6,7) were signed between the USGS and USDA agencies (NRCS and FSA) allowing the USGS access to conservation data records for all farms in the Chesapeake Bay watershed. This 
access was interpreted to include every county that intersects or falls within the Chesapeake Bay watershed boundary (fig. 1). Under the authority of these agreements, the USGS requested datasets from the FSA and NRCS, with the primary objective of obtaining data for practices implemented within the 2012 Progress Reporting Year (July 1, 2011, to June 30, 2012) and the secondary objective of obtaining as many recent years of quality data as were readily available. Considerable discussion with various State and Federal contacts (appendix A) was required in order to determine the specific information to be included in each data request.

\section{FSA Data}

The USGS requested data from the FSA on August 8, 2012 (appendix C:2). Updates to the national FSA databases are made monthly on a rolling basis, and the best timing to obtain a database of practices implemented through the end of the each progress year (June 30) is therefore to make the request after August 1, when the July monthly update has been completed. There is no particular benefit in waiting until the end of the Federal fiscal year (September 30) to make a data request.

The FSA data came from two parallel sources:

1. The FSA Farm Practices Dataset ("UnaggregatedFSAPracticeDataByState”) was obtained on August 29, 2012, from Barbara J. Clark (appendix A) in the FSA Kansas City office. The dataset included two spreadsheets of information: Practices and Customers. The six critical information fields used for data reporting included county (FIPS), practice applied date (OriginalCRPStartDate), practice code (PracticeCode), acreage (PracticeAcres), customer (CustNo), and contract number (ContractID). The dataset included FSA financially assisted CRP and CREP practices applied on agricultural land within the six-State area, with records going back to 2000. The dataset did not include practices where Federal financial assistance was not provided.

The FSA Farm Practices Dataset contained 1,212 records of practices that were applied between July 1, 2011, and June 30, 2012 (table 3) in counties that intersect or fall within the Chesapeake Bay watershed. The data were aggregated by county to protect farmer privacy, and the information was delivered to the State jurisdictions for possible use in conservation reporting. The number of reportable records by jurisdiction is presented in table 3. It was not necessary to use contract lifespan (YearContractEnd) to determine whether practices had expired because only new practice implementation was being tabulated for each of the past 3 years, rather than all practices under active contracts, and the minimum lifespan of a CRP or CREP contract is 10 years. See appendix D:1 for a listing of the FSA conservation practices that were contained in the dataset.

2. The FSA Geospatial Dataset, delivered by Dave Perry (appendix A), included annotated shapefiles of Common Land Use (CLU) field boundaries and a database file containing limited information on CRP and CREP enrollment for each county. This dataset included all existing practices but did not include a practice applied date. The CLU shapefiles can be linked to the FSA Farm Practices tabular dataset by using the unique identifier CLU_ID that is present in both datasets, providing geospatial locations for each practice. Apart from location, the practice information contained in the shapefiles is otherwise not as useful for conservation data reporting as is the tabular Farm Practices dataset. Because sub-county geospatial information was not required for the 2012 Annual Progress Review, the 2012 CLU geospatial dataset was archived and transmitted to USGS 1619 collaborators for use in watershed studies but was not used for reporting purposes. 
Table 3. Number of USDA conservation practice records within each contract program, after removal of duplication between NRCS and FSA datasets (cleaned). These totals include all practices within counties that intersect or are contained within the Chesapeake Bay watershed and are for the 2012 progress year (July 1, 2011-June 30, 2012).

\begin{tabular}{|c|c|c|c|c|c|c|}
\hline Conservation Program & $\mathrm{DE}$ & MD & NY & PA & VA & WV \\
\hline Agricultural Management Assistance & 32 & 130 & 42 & 144 & 0 & 24 \\
\hline Agricultural Water Enhancement Program & 0 & 0 & 322 & 0 & 2 & 0 \\
\hline Chesapeake Bay Watershed Initiative & 323 & 5,911 & 164 & 2,607 & 6,746 & 505 \\
\hline Conservation Reserve Program & 70 & 628 & 45 & 147 & 396 & 5 \\
\hline Conservation Security Program & 0 & 0 & 0 & 0 & 10 & 0 \\
\hline Conservation Stewardship Program & 0 & 0 & 0 & 4 & 2 & 0 \\
\hline CTA - Great Lakes Restoration Initiative & 0 & 0 & 1 & 6 & 0 & 0 \\
\hline DE-SL-District Cost-Share Program & 3,433 & 9 & 0 & 0 & 0 & 0 \\
\hline DE-SL-District Cost-Share Funded & 1,420 & 0 & 0 & 0 & 0 & 0 \\
\hline Emergency Conservation Program & 0 & 0 & 0 & 0 & 34 & 12 \\
\hline Environmental Quality Incentive Program & 1,032 & 3,036 & 2,385 & 2,845 & 2,482 & 1,195 \\
\hline Grassland Reserve Program & 0 & 0 & 28 & 1 & 8 & 0 \\
\hline MD-CE-Grazing Lands Conservation Init & 0 & 2 & 0 & 0 & 0 & 0 \\
\hline MD-SL-MACS CostShr or Prog Admin - CTA & 0 & 119 & 0 & 0 & 0 & 0 \\
\hline MD-SL-MACS-EQIP Co-Costshare & 0 & 59 & 0 & 0 & 0 & 0 \\
\hline MD-SL-MACS-WHIP Co-Costshare & 0 & 7 & 0 & 0 & 0 & 0 \\
\hline MD-SL-MACSGLC & 0 & 11 & 0 & 0 & 0 & 0 \\
\hline PA-CE-Tuplehocken Creek & 0 & 0 & 0 & 1 & 0 & 0 \\
\hline Small Watershed Operations & 0 & 0 & 0 & 49 & 0 & 0 \\
\hline VA-CE-Chesapeake Bay Activities & 0 & 0 & 0 & 0 & 184 & 0 \\
\hline VA-RN-DCR & 0 & 0 & 0 & 0 & 5 & 0 \\
\hline VA-RN-DCR/SWCD BMP & 0 & 0 & 0 & 0 & 6 & 0 \\
\hline VA-SL-GLCI & 0 & 0 & 0 & 0 & 11 & 0 \\
\hline VA-SL-US-CTA-VAAGBMP & 0 & 0 & 0 & 0 & 32 & 0 \\
\hline Wetlands Reserve Program & 4 & 8 & 29 & 11 & 16 & 2 \\
\hline Wildlife Habitat Incentives Program & 25 & 49 & 305 & 273 & 395 & 259 \\
\hline WV-CE-Chesapeake Bay Program & 0 & 0 & 0 & 0 & 0 & 48 \\
\hline FSA (CRP and CREP) & 21 & 413 & 54 & 551 & 150 & 23 \\
\hline Total number of funded practices & 6,360 & 10,382 & 3,375 & 6,639 & 10,479 & 2,073 \\
\hline Conservation Technical Assistance (CTA)* & 531 & 16,110 & 3,049 & 6,310 & 15,569 & 1,165 \\
\hline$\%$ CTA & $8 \%$ & $61 \%$ & $47 \%$ & $49 \%$ & $60 \%$ & $36 \%$ \\
\hline
\end{tabular}

${ }^{*}$ CTA practices were not reported to the 2012 Annual Progress Review.

\section{NRCS Data}

The USGS received data from the NRCS on October 19, 2012, after the close of the Federal fiscal year (September 30). System updates occur at the end of each fiscal year, and the most complete dataset is available once those updates are complete. It is therefore most effective to acquire NRCS conservation data from the National Conservation Planning (NCP) dataset [fig. 2] after October 15 of each year. This requires beginning the paperwork for the data request several months prior (July), working in collaboration with a senior NRCS counterpart who will officially author the data request (this counterpart was Arlen Ricke in 2012 and Rich Sims in 2013, appendix A).

Although the data request can be simple (appendix C:3), it is important to identify the full range of desired Farm Bill contract programs to be included (table 3), and, because programs change from year to year, to specifically request 'data for 
all conservation practices located within the Chesapeake Bay watershed.' In 2012 it was sufficient to identify 'the full range of the NRCS Chesapeake Bay Watershed Initiative programs along with Conservation Technical Assistance,' but as databases are updated and change over time, it may become necessary to name the individual programs for which data are needed. The list of 2012 programs is included in table 3. Although it is not required in the formal data request, it is also critical to communicate the breadth of data categories being requested (appendix C:1) to the NRCS point of contact (David Butler, appendix A) in order to obtain sufficient information to adequately address double counting and accurately credit conservation practices within the Chesapeake Bay model. An updated 2013 data request specifying this information is included as appendix C:5.

In response to the 2012 request, the NRCS provided data back to 2006, the earliest year from which digital data management has been consistent. The key contact person who prepared and delivered the NRCS dataset was Dave Butler (appendix A). The data were delivered in a SQL Server database backup file. The database was organized into five tables: Practices, Plan Customers, Plan Agency Affiliation, Contracts, and Contract Customers (appendix C:1). Database operations were performed by using SQL Server. Each NRCS data record contained an identifier for the sponsoring program (contract program name). The number of records per program and State contained in the dataset is listed in table 3.

The data request was limited to applied practices, and it excluded practices that had been planned but not yet applied. Because each NRCS conservation practice came with a practice applied date, it was possible to select the records that were implemented within specific annual reporting periods (July 1-June 30). Each type of conservation practice is identified by a unique practice code that is described in USDA technical documentation, and each practice code has an associated practice lifespan (appendix D:1). Although the lifespan is not necessarily an accurate identifier of whether a practice is functioning, as opposed to decrepit, it does represent the average time period that the NRCS expects the practice to be functional. This information could therefore be useful in evaluating past implementation records to determine what reported practices are still functional in the landscape.

The Chesapeake Bay Program Office designates some practices as cumulative and others as annual. Data for practices with a long lifespan and multi-year contract, such as forest buffers, waste storage facilities, and barnyard improvements, are cumulative, and their count is additive over years within the CBP Partners water-quality models. Data for practices with a one year lifespan, such as cover crops, are refreshed annually and do not accumulate. The removal of expired practices from the dataset of accumulated historical records that has been reported to the CBP Partnership over time, to avoid over-crediting within the Chesapeake Bay Watershed Model, is an issue that was identified as a priority by the National Research Council (2011).

For each Annual Progress Review, only new implementation of practices is reported. Therefore, in the 2012 data preparation, lifespan was not used to select or remove records from consideration because the records were selected on the basis of implementation date (Practice_Applied_Date) and reported within a single yearly time span (July 1-June 30), and all practices have an associated lifespan of at least 1 year.

In addition to funded programs, the NRCS also maintains records (table 3) for practices that have received Conservation Technical Assistance (CTA) without financial assistance from the NRCS. The CTA entries can sometimes include valid, verified practices that are fully farmer funded and for which the NRCS provides technical oversight. These practices are common, for example, within the Plain Sect farm community ("Plain Sect" communities are Christian groups that may eschew technology or entering into contracts with the U.S. Government), and apart from CTA records they might otherwise go unreported. The CTA entries can also include practices that are cost-shared by jurisdictional agencies and therefore present a risk of double counting.

There is currently some debate about how accurate the CTA data are, with several NRCS collaborators expressing their opinion that CTA data entry is not consistently maintained across counties and jurisdictions, and recommending that the CTA data not be used in the Annual Progress Review (personal conversations with various State and national NRCS staff throughout 2012). However, other NRCS collaborators have expressed the opinion that CTA activities are entered only when the practices meet NRCS standards and specifications and so are valid for reporting purposes, as long as processes are in place to avoid double counting. In actuality, the quality of the data probably varies by jurisdiction depending on instructions and leadership coming from the NRCS State offices. Further discussion by the CBP Partnership is warranted to develop a policy regarding use and handling of CTA data.

Although the CTA records might provide a useful measure of conservation practices implemented without Federal financial assistance, currently the CBP Partnership has decided to prohibit the inclusion of these data in the Annual Progress Review, until they can confirm that the practices meet NRCS practice standards and specifications and protocols are established for ensuring that the records are not double counted. The CTA practices were identified in the NRCS dataset by contract program name = "Conservation Technical Assistance-General."

The USGS aggregated the CTA practice records by State, and included them in the aggregated USDA dataset as a separate table for informational purposes only, with instructions that they were not for use in reporting to the CBP Partnership's 2012 Annual Progress Review. The CTA practices ranged from 8 percent (Delaware) to 61 percent (Maryland) of total USDA conservation data records (table 3), which underscores the importance of the CBP Partnership working closely with USDA and the State NRCS offices to develop procedures for confirming the quality of the CTA data and ensuring that the data do not include 
double-counted records. The NRCS CTA practices can be funded by non-NRCS sources, such as the State, EPA grants, or nongovernmental organizations.

\section{Removing Duplication Between NRCS and FSA Data Sources}

Once tabulated, the USDA conservation practice datasets were analyzed to identify potential duplication between the NRCS and FSA data. Possible duplication was identified for practices that were funded by the FSA but for which Conservation Technical Assistance (CTA) was provided by the NRCS (table 4). These practices, which included NRCS practice codes 327 , $332,380,386,391,393,412,512,610,612,643,656,657,658$, and 659, were retained in the FSA dataset and were removed from the NRCS dataset. This removal of records did not affect the NRCS dataset that was ultimately reported to the CBP Partnership, because CTA data were summarized for information only and were not reported to the Annual Progress Review. After removing potential FSA-NRCS duplicates, the remaining records (table 3) comprised the unaggregated USDA conservation practices dataset. Removal of duplication between USDA and jurisdictional datasets is discussed further below, in the section "Protocols for Removing Double Counting."

Table 4. List of practices where FSA provided financial assistance and NRCS provided technical assistance.—Continued

\begin{tabular}{|c|c|c|c|}
\hline \multicolumn{2}{|r|}{ FSA practice code and name } & \multicolumn{2}{|r|}{ NRCS practice code and name } \\
\hline CP 18C & Permanent Salt Tolerant Vegetative Cover & 327 & Conservation Cover \\
\hline CP 37 & Duck Nesting Habitat & 327 & Conservation Cover \\
\hline $\mathrm{CP} 1$ & Permanent Introduced Grasses and Legumes & 327 & Conservation Cover \\
\hline $\mathrm{CP} 2$ & Permanent Native Grasses & 327 & Conservation Cover \\
\hline $\mathrm{CP} 27$ & Farmable Wetland Pilot Wetland & 327 & Conservation Cover \\
\hline CP28 & Farmable Wetland Pilot Wetland Buffer & 327 & Conservation Cover \\
\hline CP33 & Habitat Buffers for Upland Birds & 327 & Conservation Cover \\
\hline CP42 & Pollinator & 327 & Conservation Cover \\
\hline CP4B & Wildlife Habitat Corridors Noneasement & 327 & Conservation Cover \\
\hline CP4D & Wildlife Habitat Noneasement & 327 & Conservation Cover \\
\hline CP15A & Contour Grass Strips & 332 & Contour Buffer Strips \\
\hline CP15B & Contour Grass Strips on Terraces & 332 & Contour Buffer Strips \\
\hline CP16A & Shelterbelt Establishment & 380 & Windbreak/Shelterbelt Establishment \\
\hline CP17A & Living Snow Fences, Noneasement & 380 & Windbreak/Shelterbelt Establishment \\
\hline CP5A & Field Windbreak Establishment & 380 & Windbreak/Shelterbelt Establishment \\
\hline CP33 & Habitat Buffers for Upland Birds & 386 & Field Border \\
\hline $\mathrm{CP} 22$ & Riparian Buffer (forested) & 391 & Riparian Forest Buffer \\
\hline $\mathrm{CP} 21$ & Filter Strips & 393 & Filter Strip \\
\hline CP8A & Grass Waterways, Noneasement & 412 & Grassed Waterway \\
\hline $\mathrm{CP} 1$ & Permanent Introduced Grasses and Legumes & 512 & Forage and Biomass Planting \\
\hline $\mathrm{CP} 2$ & Permanent Native Grasses & 512 & Forage and Biomass Planting \\
\hline CP27 & Farmable Wetland Pilot Wetland & 512 & Forage and Biomass Planting \\
\hline CP28 & Farmable Wetland Pilot Wetland Buffer & 512 & Forage and Biomass Planting \\
\hline CP33 & Habitat Buffers for Upland Birds & 512 & Forage and Biomass Planting \\
\hline CP $18 \mathrm{C}$ & Permanent Salt Tolerant Vegetative Cover & 610 & Salinity and Sodic Soil Management \\
\hline CP18B & Permanent Vegetation to Reduce Salinity & 610 & Salinity and Sodic Soil Management \\
\hline $\mathrm{CP} 3$ & Tree Planting & 612 & Tree/Shrub Establishment \\
\hline CP31 & Bottomland Timber Establishment of Wetlands & 612 & Tree/Shrub Establishment \\
\hline CP36 & Longleaf Pine - Establishment & 612 & Tree/Shrub Establishment \\
\hline CP3A & Hardwood Tree Planting & 612 & Tree/Shrub Establishment \\
\hline
\end{tabular}


Table 4. List of practices where FSA provided financial assistance and NRCS provided technical assistance.—Continued

\begin{tabular}{llll}
\hline & FSA practice code and name & & NRCS practice code and name \\
\hline CP4B & Wildlife Habitat Corridors Noneasement & 612 & Tree/Shrub Establishment \\
CP4D & Wildlife Habitat Noneasement & 612 & Tree/Shrub Establishment \\
\hline CP25 & Rare and Declining Habitat & 643 & $\begin{array}{c}\text { Restoration and Management of Rare and } \\
\text { Declining Habitats }\end{array}$ \\
\hline CP12 & Wildlife Food Plot & 645 & Upland Wildlife Habitat Management \\
\hline CP39 & Constructed Wetland & 656 & Constructed Wetland \\
\hline CP23 & Wetland Restoration & 657 & Wetland Restoration \\
CP23A & Wetland Restoration non-floodplain & 657 & Wetland Restoration \\
CP27 & Farmable Wetland Pilot Wetland & 657 & Wetland Restoration \\
CP41 & FWP Flooded Prairie Wetland & 657 & Wetland Restoration \\
CP9 & Shallow Water Areas for Wildlife & 657 & Wetland Restoration \\
\hline CP40 & FWP Aquaculture Wetland Restoration & 658 & Wetland Creation \\
\hline CP40 & FWP Aquaculture Wetland Restoration & 659 & Wetland Enhancement \\
\hline
\end{tabular}

\section{Data Aggregation To Protect Farmer Privacy}

According to the USGS Data Handling Agreement (appendix B:8) that was approved by FSA Privacy Officer John Underwood (appendix A), aggregated totals can be reported to the public in compliance with 1619 regulations when five or more farmers are enrolled in a particular conservation practice within a particular geographical area. (This is the simplest and most conservative interpretation and is the one that was used by this project; see appendix B:8 for the more nuanced language.) Where fewer than five farmers are implementing a specific practice, the practice must be reported at a larger geographical scale or go unreported. For the 2012 data submission, it was decided to aggregate the USDA dataset to the county level. Therefore, any conservation practices that were employed by five or more farmers in a given county were reported by county, and any records with a smaller number of associated farmers were aggregated at the statewide level.

To apply the aggregation protocol to the NRCS data records, Practice Code was joined to Customer ID (appendix C:1), and the number of unique Practice-Customer combinations per county was counted. When one farmer (Customer) implemented multiple instances of the same practice (for example, application of the same practice to multiple fields), the farmer-practice combination was tabulated only once for the purposes of determining aggregation suitability. If the total number of farmers implementing a particular practice code was greater than four, then the total number of acres or units for all occurrences of that particular conservation practice (Report Applied Amount, appendix C:1) was calculated and reported as an aggregated total.

Whenever fewer than five farmers in a county were participating in a particular practice, those records were rolled up to the State geographical scale, at which point they were reported if more than five farmers were participating in these practices among all of the "leftover" records. Only data from counties that fell within or intersected the Chesapeake Bay watershed were included. If fewer than five farmers were participating in these "leftover" practices at the State level, the data were not reported, but the number of unreported practices was quite small ( $<5$ per practice code and generally $<1$ percent of all practice records).

For each CRP and CREP practice, the FSA data were aggregated by joining Practice Code with Customer Number, then selecting distinct records of Practice Code, Customer Number, and Contract Number, and the total number of Practice Acres was reported at either the county or statewide scale for practices with five or more participating customers, following a similar logic to that employed for the NRCS dataset. The output of these protocols comprised the aggregated dataset.

\section{Transmittal of Datasets to the State Jurisdictions}

Practices implemented during the three progress years of 2010, 2011, and 2012 were provided to each jurisdiction and identified by the progress year (July 1-June 30) in which they were implemented. The aggregation protocol was applied separately to data from each progress year. The CBP Partnership has indicated that the history of reported conservation practices prior to 2010 is not eligible to be updated by the jurisdictions through NEIEN. For the 2012 Annual Progress Review, jurisdictions could update or replace NEIEN data for progress years 2010 through 2012 or could choose to report only 2012 implementation (practices implemented between July 1, 2011, and June 30, 2012). 
The USGS-processed USDA conservation practice datasets were provided to the jurisdictions in either unaggregated format (NY, MD, VA) or aggregated format (PA, DE, WV), depending on preference and status of the jurisdictional 1619 Conservation Cooperator Agreements. Integration of State and Federal datasets, including removal of State-Federal double counting, was then achieved by each jurisdiction as described further below. In all cases, USDA conservation data were aggregated by either the USGS or the jurisdictions prior to submission to the Chesapeake Bay Program Partnership.

Practices implemented as NRCS Conservation Technical Assistance (CTA) were included in the data provided to the jurisdictions for informational purposes only, as a table of statewide aggregated CTA totals. For further discussion of CTA practices, see the section "NRCS Data," above.

\section{Crosswalk Between USDA Practices and Chesapeake Bay Program Definitions}

Jurisdictions report conservation practices to the Annual Progress Review using the National Environmental Information Exchange Network (NEIEN). The input to NEIEN is then transacted and processed into the Chesapeake Bay Program Partnership's "Scenario Builder" (http://www.chesapeakebay.net/publications/title/documentation for scenario_builder), which is used to fully develop input data for the CBP Partnership's Chesapeake Bay Watershed Model. To ensure that reportable USDA conservation practices would be properly accepted by the Chesapeake Bay Program Partnership, a crosswalk between NEIEN and USDA (FSA and NRCS) practice codes and CBP Partnership's Scenario Builder definitions for non-point source conservation best management practices (BMPs) was developed and provided to the manager of NEIEN System Requirements (Martin Hurd, appendix A). Any appropriate NRCS practices that were not already available for reporting via NEIEN were added to NEIEN and mapped to the appropriate Scenario Builder practice. The 2012 crosswalk is provided in appendix E. The crosswalk will need to be updated on an annual basis to reflect progressive changes in USDA and CBP conservation practice definitions.

Some management practices that receive financial assistance from the NRCS and (or) FSA are designed to conserve resources other than nitrogen, phosphorus, or sediment and so are not transmitted from NEIEN to Scenario Builder. Some examples of practices that are not addressed by the CBP Partnership because they are not relevant to nutrient and sediment conservation include fuel storage construction, tree/shrub pruning, and fish pond management. For practices that have a nutrient and (or) sediment reduction benefit, the CBP Partnership has a long-established protocol for considering new BMPs, and it is possible to add or change BMPs that have been accepted by the CBP Partnership (Chesapeake Bay Program Water Quality Goal Implementation Team, 2010).

There are several NRCS practices that are mapped to CBP Partnership practices where the definitions do not align precisely. One important example is wetland restoration, where NRCS definitions (practice codes 644, 658, 657, and 659) allow for cost-shared removal of Phragmites from existing wetlands, but this activity does not meet the CBP Partnership definition of the wetland restoration for nutrient and sediment control. Another is cover crops, where the NRCS allows for use of legumes, but the CBP Partnership's definitions currently do not. These practices, along with a number of other BMPs, are therefore sometimes only approximate matches. A detailed description of the most important discrepancies follows further below, in the section "More Comprehensive Tracking of Practices by NRCS."

\section{Protocols for Avoiding Double Counting}

There are many situations where a jurisdiction tracks an implemented conservation practice and the USDA also tracks the identical practice. Typically, both the jurisdiction and the USDA are tracking the same practice because they both provided financial assistance to the farmer for the practice implementation. In these cases, there must be a clear protocol in place to choose which data to report in order to avoid double counting (NRCS, 2011). In 2012, the six watershed jurisdictions employed various techniques to address this issue. The solutions, which are documented here, were tailored to address specific practices that could potentially receive financial assistance from both State and Federal programs, based on the range of conservation programs available to farmers within each jurisdiction. How the jurisdictions with independent access to USDA data through their agency 1619 Conservation Cooperator Agreements chose to handle any potential duplication within NRCS and FSA data sources and to remove Conservation Technical Assistance data records, as described above in "Removing Duplication Between NRCS and FSA Data Sources," was not documented.

The most general approach for removing double counting was to compare practice codes and definitions, identify which practice types could potentially be duplicated on the basis of knowledge of program structure, and exclude all records for those particular practice codes from either the USDA dataset or the jurisdictional dataset, generally retaining the records that contain a greater level of detail. For example, a cover crop practice might be funded at 40 percent of cost by State programs and 60 percent by the NRCS. Double counting of practices that could be co-cost-shared can be avoided by excluding records for those practices from either the State or NRCS dataset. For example, in Virginia, nutrient management plans were reported from the jurisdictional dataset and removed from the USDA dataset. Once the patterns of possible double counting are identified and the 
choices of which practice codes to remove from which dataset are made, this broad-brush approach is relatively simple to implement and can be applied to aggregated datasets. The only drawback is that the method may perhaps remove some records in error, in the cases where similar practices can be either co-funded or separately funded by the USDA and jurisdictional programs (for example, cover crops in Lancaster County, PA). In those cases the separately funded instances would be removed as potential duplicates when they were in fact valid records.

Alternatively, a record-by-record comparison was employed to examine record details and determine which records were an exact match between USDA and jurisdictional datasets (the same practice applied to the same field location and acreage within the same implementation year). In those cases, all but one of the practices would be removed. This method is fairly accurate but is time consuming and requires access to the unaggregated USDA dataset (available only to 1619 Conservation Cooperators).

A third approach, available to jurisdictions that are 1619 Conservation Cooperators, was to maintain an integrated database that tracks all implemented conservation practices, whether funded by Federal or State governments or not financially assisted. In these data systems, when the Soil Conservation District staff work with farmers to implement conservation practices that receive financial assistance from both the State and Federal programs, the various funding sources are recorded as associated with a single data record, and it becomes straightforward to query the database and report implementation progress without risk of record duplication.

Each jurisdiction arrived at its own combination of methods to remove duplicate records, with generally good results. However, the process is not perfect, and continued attention to detail is required to successfully manage the complex task of obtaining and integrating implementation data for each specific type of conservation practice that is promoted by the various jurisdictional and Federal conservation agencies. The following sections document the jurisdiction-specific methods that were used to avoid double counting in 2012.

\section{Delaware}

Because they are not a 1619 Conservation Cooperator, the DE-DNREC has access only to aggregated USDA conservation data, obtained either from the USGS or from the State NRCS and FSA offices. The jurisdiction compared the USGS-provided data for 2010 and 2011 with what they had previously submitted, and the level of implementation for most practices was the same as or higher than what Delaware had previously reported, owing to differences in the data requested from the NRCS. In 2012, Delaware chose to use the USGS-provided aggregated dataset for all USDA practices in the 2012 Annual Progress Review data submission and replaced the 2010 and 2011 data with the USGS-provided data. Prior to 2010, Delaware had reported NRCS and FSA practices by using internal data sources.

In Delaware, most agricultural conservation practices were funded by either the USDA or the jurisdiction — but not bothand so duplication was not an issue. The main exception was cover crops, where financial assistance programs were offered by both the NRCS and the State. For cover crops, the State data contained a greater level of detail about specific cover crop management practices that could be used to obtain increased crediting for estimated nutrient and sediment load reductions in Scenario Builder. Delaware therefore chose to report all jurisdictional data for cover crops and to subtract the total of the State cover crop acres from the NRCS cover crop data. If there was a remainder in the NRCS cover crop acres, then those were also reported. Cover crop attributes that are not included in the NRCS data include crop variety, planting date, planting method, and commodity status (that is, whether or not the crop was sold as a commodity; however, Delaware no longer provides financial assistance for commodity cover crops as of fiscal year 2012).

Additional attention was paid to examining forestry practices in the NRCS dataset, and it was determined that there was no overlap with jurisdictional databases. Potential for overlap between the NRCS and Delaware Forest Service could be possible for forestry practices other than tree planting or forest harvesting, but those practices were not included in the NRCS dataset.

\section{Maryland}

As a 1619 Conservation Cooperator, Maryland was provided with unaggregated USDA conservation data by the USGS. However, Maryland chose not to use the dataset for reporting purposes, instead relying upon its jurisdictional integrated databases (including "Conservation Tracker," as well as databases for cover crops and manure transport) and voluntarily completed Annual Implementation Report forms, all of which are maintained by the Maryland Department of Agriculture. This data system is used to record all conservation practices (financially assisted Federal and State practices, as well as those installed without Federal or State financial assistance) regardless of the source of financial assistance, through data entry that occurs at each Service Center Office. Any submission of the USGS-provided NRCS or FSA data would therefore be a duplicate.

In Conservation Tracker, practices that receive financial assistance from multiple sources are recorded as a single record item with data on percentage of financial assistance from each source, and double counting of records is thereby eliminated. 
Because of the increased level of detail and accuracy, Maryland chose to submit only data from its jurisdictional databases to the CBP Partnership's Annual Progress Review.

The NRCS and FSA data provided by the USGS can be used by the Maryland Department of Agriculture as a management tool to assess the data quality and completeness of the Conservation Tracker dataset and to work with staff on improving reporting accuracy.

\section{New York}

As a 1619 Conservation Cooperator, the Upper Susquehanna Coalition (USC) was provided with unaggregated USDA conservation data by the USGS. However, the USC chose not to use the dataset for reporting purposes. Instead, it relied on direct query to the conservation districts. The NRCS and FSA data provided by the USGS was used by the USC to inform the direct queries of the conservation districts.

Because the portion of New York that falls within the Chesapeake Bay watershed is relatively small, the USC has established a system of meeting with the District Manager and the NRCS District Conservationist at each individual conservation district to quantify the annual implementation of both Federal- and State-supported conservation practices. Removal of StateFederal duplication was achieved during these discussions by carefully comparing programs and funded practices. The NRCS and FSA data provided by the USGS were used as a data check and helped to stimulate additional questions about conservation practice reporting in the data-collection meetings held with the conservation districts.

New York uses the State-funded Agricultural Environmental Management (NY-AEM) data system (http://www.nyssoilandwater.org) as its framework for conservation planning, data collection, and verification. In 2013, New York is transitioning to using an online toolkit linked to the NY-AEM to track and report data in a consistent format for NEIEN submission. The same protocols as 2012 will be followed, but the data will be processed through the online system.

\section{Pennsylvania}

Because it is not a 1619 Conservation Cooperator, the Pennsylvania Department of Environmental Protection was provided with aggregated USDA conservation data. The jurisdiction used the USGS-provided data in the 2012 Annual Progress submission to CBP and also used a USGS-provided dataset to report NRCS and FSA practices in 2011. Prior to 2011 the jurisdiction reported FSA and NRCS conservation practices by using NRCS county summaries that were then available on the Web.

The PA-DEP does not have a 1619 Agreement with the NRCS or FSA and, therefore, could not identify duplicates other than by using the broad-brush approach of comparing practice codes. The jurisdiction indicated that all NRCS and FSA practices were retained in the USDA dataset and that any equivalent practices were removed from Pennsylvania State data sources prior to reporting.

\section{Virginia}

As a 1619 Conservation Cooperator, the Virginia Department of Conservation and Recreation was provided with the unaggregated USDA conservation dataset. The jurisdiction performed a comparison with USDA conservation data obtained directly from the Virginia State NRCS office. The two NRCS datasets differed somewhat, because the USGS data were pulled in tabular format from the NCP database whereas the locally sourced data were obtained by using the NRCS Integrated Data for Enterprise Analysis (IDEA) geospatial interface. The jurisdiction found that they were able to link more practice data to contract data by using the locally obtained dataset than was possible with the data that the national NRCS office provided to the USGS. Virginia chose to use the State-provided NRCS data in the 2012 Annual Progress submission to CBP and did not use the USGS-provided dataset for reporting purposes.

The majority of conservation practices that could possibly receive financial assistance from both Virginia and the NRCS, and were therefore at risk for double counting, were nutrient management practices and cover crops. Virginia decided to report these practices by using the State-funded database and to remove them from the reported NRCS practice database. Enhanced nutrient management was recorded only in the USDA dataset and, therefore, was not subject to duplication. Additional practices that might receive financial assistance from both State and Federal programs were compared on a line-by-line basis, using data for farm owner/operator, location, and acreage. Potential duplicate records were flagged and removed from the NRCS database.

Starting in July 2013, the Virginia Department of Environmental Quality (VA-DEQ) will be the State agency receiving the CBP Chesapeake Bay Regulatory and Accountability Grant supporting reporting efforts and will be responsible for reporting all conservation practices for the CBP Partnership's Annual Progress Review, based on actions during the recent General Assembly and decisions between the Office of the Secretary of Natural Resources and the Directors of the VA-DCR and VA-DEQ. William Keeling (appendix A) was transferred from VA-DRC to the VA-DEQ in late June 2013. The above-described process 
for potential duplicate removal may therefore be changed for 2013 and future years, since the VA-DEQ does not have a 1619 Cooperator Agreement with the USDA. Specifics of an adjusted protocol for addressing double counting and reporting conservation data to the 2013 Annual Progress Review are currently being discussed by the VA-DCR and VA-DEQ.

\section{West Virginia}

Although West Virginia is a 1619 Conservation Cooperator through the WVDA and WVCA, the jurisdiction chose to be provided with the aggregated USDA conservation dataset due to State NRCS staffing and priorities. West Virginia validated the data by comparing the USGS-provided dataset with data obtained through NRCS field offices and the FSA State Office, and determined that the USGS-provided data were of similar quality to what West Virginia had previously reported, and in some cases included higher levels of implementation. West Virginia therefore chose to use the USGS-supplied aggregated dataset to report USDA conservation practices to the 2012 Annual Progress Review. Prior to 2012, West Virginia had reported NRCS and FSA practices using the then-publicly available "PRS" database from the NRCS Web site, as well as NRCS, FSA, and internal data sources.

To compile jurisdictional data for the Annual Progress Review, the WVDEP requested data from the WVDA and WVCA, as well as internal WVDEP sources. In 2012, the West Virginia Agricultural Enhancement Program (AEP) only funded instances of practices that were not funded by the NRCS. A cross-checking procedure is in place between the agencies at the conservation districts, and the WVCA kept records for only AEP-funded instances of practices; thus, there was no chance of duplication. Two FSA practices funded through the CREP program also were reported in West Virginia State databases: filter strips (CP-21) and riparian buffers (CP-22). The jurisdiction chose to report all USDA practices contained in the USGS-provided dataset and removed, as necessary, filter strips and riparian buffers on crop or pasture from the jurisdictional dataset prior to reporting.

\section{Final Submission of 2012 Conservation Data to the Annual Progress Review}

Each of the jurisdictions submitted records of State-funded conservation practices, along with aggregated records of USDA-funded conservation practices, to their respective State's NEIEN data nodes by December 31, 2012. The USGS-sourced dataset was used by Delaware, Pennsylvania, and West Virginia to report USDA conservation practices. Maryland, New York, and Virginia chose to rely upon their individual 1619 Conservation Cooperator Agreements to obtain direct access to USDA conservation data at the State level and used the USGS-provided data only for comparison and quality control.

Once data records are submitted to NEIEN, they are processed through the CBP Partnership's Scenario Builder, and each jurisdiction receives a report of what practices were given credit. At that point, the jurisdictions have the opportunity to modify, correct, and resubmit the data records. Modifications are typically made to correct for technical issues related to the NEIEN node format and proper attribution of conservation practice data records. However, at this point in the process, the role of the USGS in providing USDA conservation datasets to the jurisdictions is complete.

\section{3 and Onward: The Drawing Board for Further Improvements}

This project was initiated to provide the Chesapeake Bay watershed jurisdictions with consistent access to USDA conservation practice data and to streamline data reporting and ease the required time burden for Federal and jurisdictional partners to deliver data for the CPB Partnership's Annual Progress Review. Although these goals were largely accomplished, targets for future improvement were also identified. The objective for 2013 and future years is to obtain datasets of equal or better quality that are more tailored to the needs of the jurisdictions. This report provides the foundation to make documented improvements in future data-handling procedures.

\section{Improvements in Requesting Data}

In 2012, the USGS succeeded in obtaining conservation practice datasets from the USDA, processing them, and providing both aggregated and unaggregated data to the six jurisdictions. The USGS will again request and process USDA data for the 2013 Annual Progress Review. Although this past year was a success in that a comprehensive USDA dataset was compiled and delivered to the jurisdictions, there is room for continued improvement in the details of how the data are obtained and what is included in the dataset.

Generally, the 2012 dataset proved to be thorough and adequate to meet the needs of data reporting and removal of double counting. However, in Virginia, the lead responsible for data reporting (Bill Keeling, with the VA-DCR in 2012, appendix 
A) preferred a similar NRCS conservation practices dataset that was provided by the Virginia NRCS State Office Geospatial Information Systems (GIS) Specialist, Fred Garst (appendix A), using the NRCS Integrated Data for Enterprise Analysis (IDEA) interface. The IDEA dataset was preferred to the 2012 USGS-sourced dataset because the data were provided in a single table and contained more thorough information linking practices to conservation plans, a feature that was useful in removing double counting. Mr. Garst also reported that the land-use data field was populated in the IDEA database (this field is only sparsely populated in the NCP database that the USGS obtained) and that he had not noticed any internal duplication of records. The USGS is working with the USDA to improve the data request to resolve these questions and maximize the range of available information.

For the 2013 Annual Progress Review, the USGS will again obtain data in tabular format from the NCP database, using an updated data request that addresses these concerns (appendix C:5).

Anticipated timeline:

- July 15 - Submit data request to the NRCS

- July 15 - Submit data request to the FSA

- August 15 - USGS/jurisdictions receive the FSA dataset

- October 1 - CBP Partnership Scenario Builder practice definitions finalized for the year

- October 15 - CBP Verification Committee approves updated crosswalk

- October 15 - USGS/jurisdictions receive the NRCS dataset

- November 1 - USGS delivers aggregated USDA data to the jurisdictions

- December 1 - Jurisdictions submit integrated Federal-State dataset to the CBP Partnership's Annual Progress Review via NEIEN

The NRCS is currently undertaking a Conservation Delivery Streamlining Initiative (CDSI) and has plans to integrate the $\mathrm{NCP}$ and IDEA data systems (http://www.nrcs.usda.gov/wps/portal/nrcs/main/national/about/cdsi). Similarly, the FSA is reengineering its conservation practice database under the Modernize and Innovate the Delivery of Agricultural Systems (MIDAS) program (http://www.fsa.usda.gov/FSA/newsReleases?area $=$ newsroom\&subject $=$ landing\&topic $=p f$ s \&newstype $=$ prfactsheet\&ty $p e=$ detail\&item $=p f \_20120507 \_a d m i n \_e n \_m i d a s 12 . h t m l$ ). These changes at the USDA are moving toward increased clarity and detail in conservation data management, and while the implementation of practices will likely remain consistent, the associated information that will be available in future years may look quite different from the 2012 dataset. It will be important to maintain the level of discussion and collaboration achieved in 2012 to smoothly integrate these expected changes with jurisdictional datasets and facilitate data transfer between State and Federal agencies.

\section{More Comprehensive Tracking of Practices by the USDA}

In preparation for discussions with the USDA, the members of the CBP Partnership's Agriculture Workgroup have identified opportunities to enhance the recordkeeping associated with USDA conservation practices, in order to capture specific information that can be used to more efficiently integrate the data with jurisdictional datasets and to more accurately represent the practices in Scenario Builder, and in the various CBP Partnership water-quality models. A list of USDA conservation practices was identified (table 5) as having substantial limitation in the amount of data available for translating between USDA conservation practice codes and CBP Partnership approved practice definitions. These practices are discussed below. Other conservation practices not represented here may also have data limitations depending on their use and reporting. In many cases, these limitations could be addressed through simple techniques such as the use of modifying letter codes to distinguish among the various conservation techniques that fall within each practice code definition. The CBP Partnership's protocols generally assume the lowest available estimated load reductions for conservation practices whenever there is not detailed information available to support a higher conservation effectiveness estimate.

\section{Land Use and Livestock Animal Type}

Limitation: The NRCS currently has fields in its data collection system for land use and livestock type, associated with a variety of conservation practices. However, these data fields were rarely populated in the 2012 NRCS dataset provided to the USGS from the NCP database. The CBP Partnership definitions place practices in the context of land use (for example, pasture fencing receives a reduction for $\mathrm{CBP}$ only when applied to riparian areas). 
Opportunities: Populating the data fields for land use and livestock type could allow the six watershed jurisdictions to receive more accurate crediting for many different conservation practices whenever conservation practice efficiency in reducing nutrient and sediment loads is modified by land use (for example, farm headquarters, forest, crop/hay, range/pasture) or animal type (for example, manure management, feed management). Currently, default values are assigned to unreported elements by using conservative effectiveness values. Although populating these fields would represent additional effort on the part of NRCS staff, the benefit could be more accurate recognition of increased pollutant load reductions from agricultural lands.

The current land-use and animal-type information may possibly exist in other NRCS datasets such as the IDEA system, in which case the problem becomes one of linking the data to the NCP records rather than ensuring data entry in the Service Center Offices. The land use changes "from" and "to" do not presently exist in NRCS databases, only the current land use. The livestock animal type is available in ProTracts, but is not in Toolkit or the field is not populated in the NCP database. The number of animals or animal units associated with a livestock conservation practices could also be useful for obtaining full nutrient conservation credits in the CBP Partnership's water-quality models. [Note: data for land use and livestock types were successfully acquired in October 2013. This acquisition was made possible by changes in the NRCS database that fully linked the land use and livestock type to the practice implementation data. However, numerous cases of missing land use and livestock type data entries persisted.]

\section{Cover Crops}

Limitation: The NRCS currently defines, tracks, and reports cover crops under a single conservation practice code (340) and standard. The Chesapeake Bay Program Partnership currently defines cover crops by four attributes (species, planting method, timing of planting, and harvest strategy) to determine their effectiveness in reducing the loss of nutrients and sediments to the environment. In particular, the NRCS lumps leguminous cover crop types with all cover crops. The CBP does not currently consider leguminous cover crops as having a nitrogen benefit since they fix nitrogen in the soil. These additional attributes presently are not currently available in any NRCS business tool.

Opportunities: Enhancements to record keeping for the USDA conservation practice code for cover crops that could track and report additional management details identifying all four cover crop attributes, or even a single attribute such as species, could allow the six watershed jurisdictions to receive more accurate crediting of cover crops and more thorough representation in the Chesapeake Bay Program Partnership's models. In Scenario Builder, conservative default values are assigned to unreported elements when clarifying information is not available. At present, NRCS staff have indicated that they are unlikely to track cover crops with more specificity because the present system does not allow for enhancements to record keeping.

\section{Fencing}

Limitation: The NRCS currently defines, tracks, and reports fencing practices under a single conservation practice code (382) and standard, whereas the Chesapeake Bay Scenario Builder defines the nutrient benefits associated with fencing as a component of the management change the practice creates. Examples include the establishment of riparian buffers versus rotational grazing of livestock.

Opportunities: Enhancements to recordkeeping for the USDA conservation practice code for fencing that could identify the location and use of the fencing, or the associated components of the management system, could allow for better utilization within the CBP water-quality models. One example would be to link riparian forest buffers (391), riparian herbaceous cover (390), or stream crossings (578) by using a modifier to the fencing code representing riparian fencing. For grazing and pasture management improvements, the fencing code could be linked with prescribed grazing (528) or animal trails and walkways (575). Other conservation practices that potentially could be associated with fencing-related agricultural land management changes include watering facilities (614) and spring developments (574). The Pennsylvania State Office for USDA-NRCS has been investigating opportunities to enhance data collection for conservation practice code 382 (fence) through linkage to associated conservation management practices. The NRCS maintains a practice code for access control (472) where animals are excluded from the stream corridor, but the other information is not currently present in any NRCS business tool.

\section{Nutrient Management}

Limitation: The NRCS currently defines, tracks, and reports nutrient management under a single conservation practice code (590) and standard, with additional codes for Comprehensive Nutrient Management (304) and Nutrient Management Planning $(104,105)$. The CBP Partnership currently defines nutrient management under three management levels including crop group nutrient application management, enhanced application nutrient management, and decision/precision agricultural nutrient application management, with different associated effectiveness values for reducing nutrient losses to the environment. The 
'crop group nutrient application management' category was recently developed to replace the former category of nitrogen-based nutrient management. The CBP Partnership is also currently reviewing the enhanced and decision/precision nutrient application management practices, and will likely revise the definitions for these practices so they are more focused on the use of field-scale nutrient applications.

Opportunities: Enhancements to recordkeeping for the USDA conservation practice codes for nutrient management that could more readily identify differences among the three tiers of practice categories, and allow for improved data utilization by the jurisdictional partners and within the CBP Partnership's water-quality models. The new nutrient management standards for practice 590 standards have substantially expanded the categories of nutrient management that are eligible for NRCS technical support, but without an associated identifying code that can be used for reporting. Nutrient management plans for cropland are contracted as NRCS activities 104 (written) or 105 (applied) using a single practice code, which does not allow for differentiation among the planning strategies identified in the CBP Partners' nutrient management planning definitions. An example of possible practice code enhancements was developed by the Maryland State Office of USDA-NRCS to track and report multiple (four) nutrient management categories through the use of a letter suffix to the conservation practice code.

\section{Feed Management}

Limitation: The NRCS currently defines, tracks, and reports feed management under a single conservation practice code (592) and standard for multiple livestock species and does not typically track and report the type and amount of manure nutrient reductions resulting from changes in feed management. Feed management systems can focus on nitrogen and phosphorus individually or in combination, leading to different results. The CBP Partnership defines feed management effectiveness as the change in pounds of nitrogen and phosphorus reduced in a particular animal type's manure as a result of the reduction or enhancement of feed nutritional components.

Opportunities: Enhancements to recordkeeping for the USDA conservation practice code for feed management that could identify differences in feed management focused on nitrogen and phosphorus separately or in combination, and could track and report changes in manure nutrient concentrations as a result of the practice, could allow for improved data utilization by the jurisdictional partners and within the CBP Partnership's water-quality models. Associated livestock type and number could also be useful. The Pennsylvania State Office of USDA-NRCS has taken the initiative to obtain copies of farm feed management plans and to work with agricultural technical service providers to record and analyze theses data and enable tracking of the results. This information is currently not available in any NRCS business tool.

\section{Forestry Practices}

Limitation: Forest buffers are tracked by the FSA in units of acres. As part of the 2007 Forest Directive adopted by the CBP Partnership Executive Council, forest buffer goals were established and are tracked by length and width of stream miles buffered, rather than acres. Also, in the FSA CRP/CREP database, the distinction between new forest buffers versus re-enrollment of existing forest buffers is not recorded consistently, so avoiding double counting can be difficult.

Opportunities: Jurisdictions provide the length and width of implemented forest buffers to the CBP Forestry Workgroup for assessment of goal achievement. However, jurisdictions rely on the FSA data for reporting to the CBP Partnership's Annual Progress Review. The tracking of forest buffer length and width by the USDA-FSA could provide more precise information that could take into account different load reductions for narrower versus wider buffers (for example, 35 feet versus 100 feet). In addition, potential double counting between historic and current implementation could be avoided if the FSA were to record consistently and accurately whether a buffer was re-enrolled as opposed to newly installed. A similar issue of re-enrollment may exist for land retirement.

\section{Wetlands}

Limitation: The NRCS currently defines, tracks, and reports wetland conservation practices under four separate conservation practice codes $(644,658,657$, and 659) and standards. The CBP Partnership currently defines wetland conservation practice efficiencies on the basis of a single practice of wetland restoration that includes restoration, enhancement, or creation of wetlands, and distinguishes between streamside and other areas. The NRCS practice definition includes Phragmites spraying for invasive weed control, whereas the CBP Partnership definition does not accommodate Phragmites spraying. The CBP Partnership is addressing this discrepancy through its wetlands workgroup.

Opportunities: Enhancements to the CBP Partnership's practice definitions for wetlands could enable more accurate calculation of nutrient and sediment loads associated with the variety of NRCS wetland conservation practices and could allow for improved data utilization by the jurisdictional partners and within the CBP Partnership's water-quality models. 


\section{Tillage}

Limitation: The NRCS tillage practice definitions do not define the minimum amount of residue remaining on the field. All Chesapeake Bay Program tillage BMPs include a minimum residue coverage percent. This is because water-quality benefits are most tied to the residue coverage.

Opportunities: Refine the NRCS tillage practice definitions to include the minimum residue coverage. Because a high degree of soil cover dramatically increases water infiltration and storage and decreases soil erosion and soil-bound nutrient losses, encouraging the use of tiers of residue management could benefit water-quality conditions

Table 5. Possibilities for improved recordkeeping for USDA conservation practices.-Continued

\begin{tabular}{|c|c|c|c|}
\hline Land Use & Many & $\begin{array}{l}\text { Record land use and land use change } \\
\text { "from" and "to," and integrate } \\
\text { datasets to make land use information } \\
\text { consistently available in the National } \\
\text { Conservation Planning (NCP) dataset. }\end{array}$ & $\begin{array}{l}\text { NRCS has a data field for land use identifica- } \\
\text { tion (ID), but it is generally not populated in } \\
\text { the NCP database. The change "from" and } \\
\text { "to" are not available in any NRCS business } \\
\text { tool. }\end{array}$ \\
\hline Cover Crops & 340 & $\begin{array}{l}\text { Record cover crop management details in- } \\
\text { cluding species, planting date, planting } \\
\text { method, commodity versus regular, and } \\
\text { if manure was applied (for example., } \\
\text { commodity early drilled rye-aerial-no } \\
\text { manure). }\end{array}$ & $\begin{array}{l}\text { Cover crop is defined broadly in NRCS } \\
\text { data, whereas the CBP applies nitrogen } \\
\text { conservation effectiveness values that range } \\
\text { from } 5 \% \text { to } 45 \% \text {, depending on manage- } \\
\text { ment. This information is currently not } \\
\text { available in any NRCS business tool, so } \\
\text { Scenario Builder assigns conservative esti- } \\
\text { mates for NRCS cover crops. }\end{array}$ \\
\hline Fencing & 382 & $\begin{array}{l}\text { Identify the location and use of the fenc- } \\
\text { ing, or the associated components of } \\
\text { the management system. }\end{array}$ & $\begin{array}{l}\text { NRCS currently defines, tracks, and } \\
\text { reports livestock fencing under a single } \\
\text { Conservation Practice Code (382). The } \\
\text { practice Access Control could show where } \\
\text { animals are excluded from stream corridor, } \\
\text { but this currently is not in any current } \\
\text { NRCS business tool. }\end{array}$ \\
\hline Nutrient Management & $590,104 / 105$ & $\begin{array}{l}\text { Differentiate various nutrient management } \\
\text { planning and implementation strategies } \\
\text { to match CBP Partnership definitions. }\end{array}$ & $\begin{array}{l}\text { NRCS currently defines, tracks, and re- } \\
\text { ports nutrient management under a single } \\
\text { Conservation Practice code (590), and } \\
\text { nutrient management plans are contracted as } \\
\text { practice } 104 \text { (written) and } 105 \text { (applied). }\end{array}$ \\
\hline Forestry Practices & CP-22 & $\begin{array}{l}\text { Record length and width of the buffer } \\
\text { rather than acreage. Indicate consis- } \\
\text { tently and accurately if a buffer is } \\
\text { re-enrolled versus newly installed. }\end{array}$ & $\begin{array}{l}\text { Forest buffers are currently tracked by FSA } \\
\text { in units of acres. Including length and } \\
\text { width would take into account different } \\
\text { load reductions for narrower versus wider } \\
\text { buffers. Double counting could be avoided } \\
\text { if FSA indicates consistently and accurately } \\
\text { whether a buffer is re-enrolled versus newly } \\
\text { installed. }\end{array}$ \\
\hline
\end{tabular}


Table 5. Possibilities for improved recordkeeping for USDA conservation practices.-Continued

\begin{tabular}{llll}
\hline Category & USDA code & Possibility & Relation to currently collected data \\
\hline Tillage Practices & $\begin{array}{c}324,329,345, \\
346,761,778\end{array}$ & $\begin{array}{l}\text { Include the residue cover amount in the } \\
\text { practice standard to indicate minimum } \\
\text { percent of cover remaining after } \\
\text { harvest. }\end{array}$ & $\begin{array}{c}\text { Current NRCS practice standards for tillage do } \\
\text { not include a minimum amount of residue } \\
\text { remaining after harvest. CBP Partnership } \\
\text { Expert Panels have found that water-quality } \\
\text { benefits for tillage practices vary greatly } \\
\text { depending on the amount of cover, and } \\
\text { jurisdictions can more accurately show } \\
\text { improvement if they have this information. }\end{array}$ \\
\hline
\end{tabular}

\section{Continuing to Improve Practice Definitions}

The definition and crediting of conservation practices within the CBP Partnership's water-quality models via the NEIEN and Scenario Builder data exchange and crediting system is a process that is under continuous development, negotiation, and improvement through coordination with the CBP Partnership's Watershed Technical Workgroup (http://www.chesapeakebay.net) groups/group/watershed_technical_workgroup) and Water-quality Goal Implementation Team (http://www.chesapeakebay.net) groups/group/water_quality_goal_implementation_team).

Because the USDA promotes a wide variety of conservation practices not always focused on nitrogen, phosphorus, and sediment control, and because the various datasets are sometimes kept in different measurement units and with more or less detail, the translation of USDA practice codes to NEIEN and CBP Partnership's Scenario Builder format is not always straightforward. However, a formal process of definition, verification, and accounting is in place, overseen by the CBP Partnership's Watershed Technical Workgroup, with a robust capacity for adaptive change and incorporation of new conservation practices as they become available.

Further discussion might be warranted regarding the current CBP Partnership's definition of cover crops and wetland restoration. For example, wetland restoration by the NRCS can include weed control (for example, Phragmites) for habitat restoration, and cover crops financed by the NRCS can include nitrogen-fixing legumes, but neither of those practices meet CBP Partnership approved practice definitions for nutrient and sediment reductions. However, a large proportion of the NRCS wetland and cover crop practices do meet CBP Partnership guidelines and can be credited. Unless the implementation datasets are kept in greater detail (as is happening under jurisdiction data management initiatives in MD and NY), the manner in which these NRCS practices are credited is a matter for negotiation within the CBP Partnership.

As jurisdictions interact with the CBP Partnership's Chesapeake Bay Program Office staff to prepare for each Annual Progress Review data submission, as conservation practice financial assistance programs are modified and developed, and as new practice definitions are adopted by the CBP Partnership, the system will continue to evolve in response. In 2013, discussion and modification of practice definitions will be allowed only until October 1, at which point the crosswalk document that translates USDA conservation practices to the CBP Partners' BMP definitions (appendix E) will be updated for approval by the CBP Partnership's technical workgroups and the Water-quality Goal Implementation Team for use in the 2013 Annual Progress Review.

\section{Increasing Information Availability to the Public}

An important goal of conservation data reporting is making the information available to the public. Conservation data products that maintain farmer privacy while describing conservation progress can help farmers and conservationists to understand and document the role that agricultural conservation plays in attaining water-quality objectives.

Tracking conservation practice implementation is important for a variety of reasons that are completely separate from TMDL regulations. Although the immediate impetus for such tracking is the CBP Partnership's Annual Progress Review, the long-term goal is improving local and Chesapeake Bay water-quality through all possible means. Increased knowledge of what practices have been implemented can help to guide water-quality planning. While keeping the private information confidential, the aggregated data could be made available on public Web sites for use by land managers.

Aggregation to subwatershed scale, rather than county scale, could assist watershed planners and scientists in linking conservation practice implementation to water-quality outcomes. It could be possible to create a mechanism for Web-enabling 
access to aggregated data, making the information about current levels of implementation more publically available. Flexible tools for public watershed planning and conservation practice implementation that integrate this information could facilitate progress toward water-quality improvements. The USDA conservation practice data described in this report are also being made available to USGS scientists who, as 1619 Conservation Cooperators, are using the information in a confidential manner, to support Chesapeake Bay watershed studies and landscape conservation initiatives.

\section{Conclusions}

In 2012, the coordinated partnership of Federal and State efforts resulted in a successful reporting of agricultural conservation practices that had been recently implemented on Chesapeake Bay farms and farmland. Although the process was not perfect, the diverse data reporting strategies employed by the jurisdictions were all successful in reporting conservation practices while largely avoiding double counting of records for which financial assistance was provided by both Federal and State agencies. These methods have now been documented, and possible improvements for future years have been identified.

For the three jurisdictions that used the USGS-sourced dataset for reporting purposes (DE, PA, and WV), streamlining the conservation data collection process enabled the development of a more consistent and complete dataset. These jurisdictions were able to report implementation of USDA conservation practices more thoroughly than they previously had, improving their ability to track progress towards achieving water-quality objectives.

The remaining three jurisdictions (MD, NY, and VA) chose not to use the USGS-sourced dataset for reporting purposes, instead relying upon USDA conservation practice information that they obtained independently using their jurisdictional 1619 Conservation Cooperator Agreements. In the case of Virginia, the jurisdiction could have used USGS-sourced data for simplicity's sake if their double-counting procedure had not entailed line-by-line comparison of records for which the Statesourced USDA dataset contained more detailed relationships between contracts and practices. The USGS is currently working with the NRCS to improve the USGS-USDA data request to obtain any missing detail to facilitate double-counting removal in Virginia and other jurisdictions in future years.

In Maryland and New York, the jurisdictions obtained USDA data from their own State-sponsored reporting systems, into which data are input by their Soil Conservation District offices. Because these databases contained both Federal and State conservation practices, they were able to remove double counting and calculate aggregated totals through a statewide database query, in the case of Maryland's Conservation Tracker system, or on a county by county basis, in the case of New York. Double-counting issues were therefore handled internally and were not documented in this report. In future years, it may be beneficial to expand the documentation of methods used to remove double counting of conservation records to include a more through description of jurisdictional conservation datasets. It is also worth noting that Lancaster County Conservation District in Pennsylvania has developed a comprehensive conservation planning and tracking system of comparable detail (PLANT, http://www.nacdnet.org/dmdocuments/Revolutionizing_Conservation_Planning_AH.pdf), but those data were not used by the Pennsylvania Department of Environmental Protection in its submission for the CBP Partnership's Annual Progress Review. Jurisdictions with combined State-Federal conservation tracking systems do not require USGS involvement in providing a USDA data product. In any case, the USGS-USDA 1619 Conservation Cooperator Agreements are set to expire in 2015, by which time direct transfer of data from USDA to the jurisdictions will be required.

However the data are obtained, accurate, consistent, detailed information on conservation practice implementation can improve the knowledge used for planning and targeting conservation practices, promoting sustainable agricultural management strategies, and supporting an adaptive management approach to improving water-quality in the Chesapeake Bay watershed. Tracking conservation progress provides the information necessary for prioritizing BMP implementation across the landscape and comparing implementation to pollutant load trends and water-quality response. This project has documented a strategy for obtaining and handling USDA farmland conservation data and for integrating these data with State conservation datasets, for the purpose of reporting them to the public in an aggregated format that protects farmer privacy while also documenting the tremendous progress that is being achieved in conservation farming. This information is one part of a larger discussion of implementation and verification of the diverse range of Federal, State, and privately funded conservation practices that are adopted by Chesapeake Bay farmers, whether in response to regulation, incentive, or stewardship of the land. 


\section{Acknowledgments}

Executive Order \#13508 prioritized Federal collaboration in support of the Chesapeake Bay Program. Thanks to Scott Phillips, Ken Hyer, and Joel Blomquist, USGS, for their leadership in developing the USGS Chesapeake Pay Science Plan and to the USGS Priority Ecosystem Studies program for supporting this work. Thanks to Rich Batiuk, EPA Chesapeake Bay Program Office, for his excellent input and support of this project, and to Renee Thompson, USGS, for paving the way with her work on the 2011 conservation dataset. The work was funded by USGS Priority Ecosystem Studies and by an interagency agreement with the EPA Chesapeake Bay Program.

Thanks to Dana York, Leonard Jordan, USDA NRCS, and Dave Kirtland, USGS, for their roles in establishing the USGS-USDA 1619 Conservation Cooperator Agreements without which this project would not have been possible. Thanks to the USDA REAP team for their initial descriptions of the various available USDA datasets and their review of aggregation protocols. And thanks to Kelly Shenk, EPA Region 3 Water Protection Division, Mark Dubin, University of Maryland/ Chesapeake Bay Program Office, Susan Marquart, Pennsylvania NRSC State office, and Anne Swanson, Chesapeake Bay Commission, for continuing to provide the discussion to move these projects along. Thanks to the Chesapeake Bay Program Partnership's Verification Committee and many other individuals who provided review and comments on the draft versions of this report.

The project is indebted to several people at the USDA, including John Underwood, FSA, David Butler, NRCS, and David Parry, FSA, for their hard work in reviewing permissions and providing datasets, as well as helping to educate us on the necessary details. Special thanks go to Richard Sims and Leonard Jordon for their work in initiating this project, reviewing this report, and providing much needed assistance along the way. The project is likewise indebted to numerous people at the jurisdictional agencies for having the patience to engage in prolonged and thorough discussion of the many details involved in accurately reporting the variety of conservation practices employed by thousands of Chesapeake Bay watershed farmers.

\section{References}

Chesapeake Bay Program Water Quality Goal Implementation Team, 2010, Protocol for the development, review, and approval of loading and effectiveness estimates for nutrient and sediment controls in the Chesapeake Bay Watershed Model: Accessed October 31, 2013, at http://www.chesapeakebay.net/channel_files/19491/nutrient-sediment_control_review_protocol_with_ addendums_05092013.pdf.

Chesapeake Bay Program Water Quality Goal Implementation Team, 2013, Minutes of the Water-quality Goal Implementation Team: Accessed October 31, 2013, at http://www.chesapeakebay.net/groups/group/water_quality_goal_implementation_team.

Chesapeake Bay Program Watershed Technical Workgroup, 2013, Minutes of the Watershed Technical Workgroup, August 13, 2013: Accessed October 31, 2013, at http://www.chesapeakebay.net/S=0/calendar/event/19142.

National Research Council, 2011, Achieving nutrient and sediment reduction goals in the Chesapeake Bay-An evaluation of program strategies and implementation: National Research Council, Committee on the Evaluation of Chesapeake Bay Program Implementation for Nutrient Reduction to Improve Water-quality, Washington, D.C., National Academies Press, 246 p.

U.S. Environmental Protection Agency, 2009, Letter to the States in the watershed and District of Columbia, December 29, 2009: Accessed October 31, 2013, at http://www.epa.gov/region03/chesapeake/bay_letter_1209.pdf.

U.S. Environmental Protection Agency, 2010, Chesapeake Bay TMDL for nitrogen, phosphorus and sediment: Accessed October 31, 2013, at http://www.epa.gov/reg3wapd/tmdl/ChesapeakeBay/tmdlexec.html. 


\section{Appendix A: Key Contacts}

\section{U.S. Geological Survey (USGS)}

Dean Hively, Research Physical Scientist, USGS Eastern Geographic Science Center. Posted to USDA-ARS Hydrology and Remote Sensing Laboratory, Bldg 007, Room 104, BARC-W, 10300 Baltimore Avenue, Beltsville, MD 20705, phone 301-5049031, email whively@usgs.gov [instrumental in project coordination, communication, analysis, and drafting of report].

Olivia H. Devereux, Environmental Scientist, Devereux Environmental Consulting (contractor to USGS through Cherokee Nation Contract \#G12PA0003), phone 301-325-7449, email olivia@devereuxconsulting.com [instrumental in data processing, communication, analysis, and drafting of report].

Peter Claggett, Geographer, USGS Eastern Geographic Science Center, phone 410-267-5771, email pclagget@usgs.gov [instrumental in establishment of USGS 1619 agreement and initial project organization].

Renee Thompson, Geographer, USGS Eastern Geographic Science Center, phone 410-267-5749, email rthompson1@usgs.gov [instrumental in developing data aggregation techniques].

Dave Kirtland, Director, USGS Eastern Geographic Science Center, 12201 Sunrise Valley Drive, MS 521 Reston, VA 20192, phone 703-648-4712, email dakirtland@usgs.gov [instrumental in establishment and oversight of USGS 1619 agreement].

\section{U.S. Department of Agriculture, Farm Service Agency (FSA)}

John Underwood, FSA Privacy Officer, phone 816-926-6992, email john.underwood@kcc.usda.gov [the one and only best contact for approval and authorization of 1619 Conservation Cooperator Agreements and data aggregation requirements, for NRCS as well as FSA data].

Barbara J. Clark, USDA/MSD/KCASB/IMS, Government Information Specialist, Farm Service Agency, 9240 Troost Ave., Mail Stop 8368, Kansas City, MO 64131-3055, phone 816-926-2636, email barbara.clark@kcc.usda.gov [main contact for formatting the FSA Farm Practices data request, which was submitted to RA.mokansasc2.fsakcfoia@one.usda.gov].

David Parry, Customer Service Supervisor, USDA Farm Service Agency Aerial Photography Field Office, 2222 West 2300 South, Salt Lake City UT 84119-2020, phone 801-844-2923, email david.parry@slc.usda.gov, Web site http://www.apfo.usda. gov [responsible for and delivered the FSA geospatial dataset, receives CREP and CLU data from State GIS leads to update national database].

Chris(tina) Rotz, Agricultural Program Specialist, Pennsylvania, USDA-Farm Service Agency, phone (717)237-2165, email christina.rotz@pa.usda.gov [Pennsylvania State GIS Specialist, collects data from the counties and prepares the monthly data submission of FSA conservation practices that is transmitted to the national database in Utah; she was a useful consultant on the understanding the appropriate timing of a data request (August) to reflect FSA practices implemented before the June 30 reporting deadline].

Charles "Michael” Boyles, FSA/ ITSD/ADC/PSCAO Farm Service Agency, 6501 Beacon Drive Kansas City, MO 64133, phone 816-926-1905, email Mike.Boyles@kcc.usda.gov [useful contact for CREP program details].

\section{U.S. Department of Agriculture, Natural Resources Conservation Service (NRCS)}

David Butler, NRCS Information Technology Center, Fort Collins, CO, phone 970-295-5545, email david.butler@ftc.usda.gov [key point of contact for obtaining NRCS conservation practice data, provided 2012 dataset to USGS].

Arlen E. Ricke, Natural Resource Manager, NRCS, Washington, DC, phone 202-720-1868, email arlen.ricke@wdc.usda.gov [NRCS signatory on 2012 USGS data request]. 
Richard Sims, Regional Conservationist for the Northeast, NRCS Office of the Chief, Washington, DC, phone 515-284-6655, email Richard.Sims@id.usda.gov [instrumental in maintaining NRCS leadership in this project and supporting 1619 negotiations in 2013].

Leonard Jordan, Associate Chief for Conservation, NRCS Office of the Chief, Washington, DC, phone 706-546-2272, email leonard.jordan@wdc.usda.gov [instrumental in establishing the 1619 Conservation Cooperator Agreements with the USGS that were signed in 2010].

Brandon J. Schneider, J.D., M.B.A., CIPP/G, Privacy Specialist, Vistronix, Department of Agriculture/NRCS, cell 703-4475878 [instrumental on 2012 USGS data request].

Michael A. Sheaver, Security Operations Branch Chief, NRCS, phone 202-720-0040, cell 703-200-3008, email Michael. Sheaver@wdc.usda.gov [instrumental on 2012 USGS data request].

Susan Marquart, Natural Resource Specialist, Pennsylvania Chesapeake Bay Coordinator, USDA Natural Resources Conservation Service, One Credit Union Place, Suite 340, Harrisburg, PA 17110-2993, phone 717-237-2237, fax 717-237-2238, email Susan.Marquart@pa.usda.gov [involved in discussion of data availability and 1619 agreements].

Denise Coleman, NRCS Pennsylvania State Conservationist, phone 717-237-2203 [involved in 1619 discussions with Pat Buckley].

Barry Frantz, Assistant State Conservationist, Programs, Harrisburg, PA 17110-2993, phone 717-237-2216, email barry. frantz@pa.usda.gov [provided comments about interpretation of lifespan].

Mary Grande, NRCS Business Tools Specialist, Ft. Collins, CO, phone 970-295-5626 [provided input on fig. 2].

NRCS REAP Program staff were helpful consultants on available NRCS database structure and on aggregation protocol recommendations: Janet Perry, NRCS Resource, Analysis and Policy Division, Washington, DC, phone 301-504-2314, email janet.perry@wdc.usda.gov; Tish Toomer-Jones, REAP Team Leader, phone 301-504-1233; Lynn Knight, phone 301-504-0393 [works on national statistics]; Leroy Hall, phone 301-504-0291 [works with Lynn Knight and Janet Perry].

Dana York, President, Green Earth Connections, LLC, 108 South Liberty Street, Centerville, MD 21617, phone 410-708-6794, email dyork818@yahoo.com [at the outset of this project, worked for the NRCS and was instrumental in promoting the dialogue between the USGS and the USDA that led to the signing of the 1619 Conservation Cooperator Agreements that support USGS access to conservation data for Chesapeake Bay farmlands].

\section{U.S. Environmental Protection Agency (EPA)}

Rich Batiuk, Associate Director for Science, U.S. Environmental Protection Agency, Chesapeake Bay Program Office, 410 Severn Avenue, Suite 109, Annapolis, MD 21403, phone 410-267-5731 or 1-800-968-7229 ext. 731, cell 443-223-7823, fax 410267-5777, email batiuk.richard@epa.gov; Web sites www.chesapeakebay.net, www.epa.gov/chesapeake [chairs the Chesapeake Bay Program Partnership's BMP Verification Committee; responsible for bringing the CBP Partnership's BMP Verification Framework through the CBP Partnership's adoption and jurisdictional implementation; provided advice and input to this report].

Jeffrey S. Sweeney, Nonpoint Source Data Manager, U.S. Environmental Protection Agency, Chesapeake Bay Program Office, 410 Severn Avenue, Suite 109, Annapolis, MD 21403, phone 410-267-9844, email jsweeney@chesapeakebay.net [EPA model input coordinator, contributed to crosswalk development].

Kelly Shenk, Regional Agricultural Advisor, U.S. Environmental Protection Agency Region III, Chesapeake Bay Program Office, 410 Severn Avenue, Suite 3CB00, Annapolis, MD 21403, phone 410-267-5728, email shenk.kelly@epa.gov [provided advice and input to this report]. 


\section{EPA Contractors and Grantees}

Matthew Johnston, Nonpoint Source Data Analyst, University of Maryland/Chesapeake Bay Program Office, 410 Severn Avenue, Suite 112, Annapolis, MD 21403, phone 410-267-5707, email mjohnston@chesapeakebay.net [will be managing the 2013 Progress Submission for the Chesapeake Bay Program].

Martin Hurd, Business Analyst, Tetra Tech, 1800 Diagonal Rd., Ste. 500, Alexandria, VA 22304, phone 703-385-6000, email martin.hurd@tetratech.com [NEIEN coordinator, contributed to crosswalk development].

Vladimir Royzman, Business Analyst, Tetra Tech, U1800 Diagonal Rd., Ste. 500, Alexandria, VA 22304, phone 703-385-6000, email vladislav.royzman@tetratech.com [will be the NEIEN coordinator for the 2013 Progress Submission].

Mark Dubin, Agricultural Technical Coordinator, University of Maryland/Chesapeake Bay Program Office, 410 Severn Avenue, Suite 112, Annapolis, MD 21403, phone 410-267-9833, email mdubin@chesapeakebay.net [provided advice and input to this report].

\section{State Agencies}

\section{Delaware}

Marcia Fox, Delaware Department of Natural Resources and Environmental Control (DE-DNREC), 89 Kings Highway, Dover, DE 19901, phone 302-739-9939, email marcia.fox@state.de.us [responsible in 2013 for collecting data, aggregation, and submission to NEIEN].

Jennifer Volk, Environmental Quality and Management Specialist, University of Delaware, 69 Transportation Circle, Dover, DE 19901, phone 302-730-4000, email jennvolk@udel.edu [in 2012, worked for the DE-DNREC and was responsible for collecting data, aggregation, and submission to NEIEN].

Paul M. Petrichenko, Assistant State Conservationist, NRCS, Dover, DE, phone 302-678-4180 [as the NRCS State lead for agricultural conservation practice data, provided NRCS data to the DE-DNREC in previous years; in 2012, helped to review USDA aggregated data provided by the USGS and provide background clarifying information about practices and expected implementation levels].

\section{Maryland}

John Rhoderick, Administrator, Resource Conservation Operations, Maryland Department of Agriculture (MDA), Office of Resource Conservation, phone 410-841-5876, email John.Rhoderick@maryland.gov [coordinates MDA team responsible for data preparation (Beth Horsey, Mike Stanton, Dawn Bradley)].

Elizabeth [Beth] Horsey, Agricultural Watershed Implementation Plan Coordinator, MDA Office of Resource Conservation, phone 410-841-5865, email elizabeth.horsey@maryland.gov [assists in the review of progress reporting].

Mike Stanton, Agricultural Watershed Implementation Program Coordinator, MDA Office of Resource Conservation, phone 410-841-5879, email Michael.Stanton@maryland.gov [administers the Conservation Tracker database, assembles and prepares data for the NEIEN submission, and delivers aggregated data to Gregorio Sandi].

Dawn Bradley, Admin. Officer for Conservation Grants, MDA, phone 410-677-0802 ext. 3, or 410 -841-5946, email Dawn. Bradley@maryland.gov [manages MDA cover crop database].

Gregorio [Greg] Sandi, Natural Resources Planner, Environmental Science Services Administration, Maryland Department of the Environment (MDE), 1800 Washington Blvd., Baltimore, MD 21230, phone 410-537-3742, fax 410-537-3873, email gregoriosandi@maryland.gov [submits aggregated database to NEIEN, took over duties from Robin Pellicano in 2012].

Robin Pellicano, MDE, 410-537-4215, robinpellicano@maryland.gov [responsible for NEIEN submission prior to 2012]. 


\section{New York}

Aaron Ristow, Ag Coordinator, Upper Susquehanna Coalition, 1771 Hanshaw Road, Ithaca, NY 14850, office phone 607257-2340, cell 607-745-7165, email aaronristow@tcswcd.org, Web site www.u-s-c.org [develops and maintains data collection system, removes double counting, collects data from Eastern districts].

Chris Yearick, GIS Specialist, Upper Susquehanna Coalition, Cornell Cooperative Extension Chemung County, 425 Pennsylvania Ave, Elmira, NY 14904, phone 607-734-4453, email cdy3@cornell.edu [manages database, submits aggregated data to NEIEN, collects data from Western districts].

Jacquelyn Lendrum, Research Scientist, New York Department of Environmental Conservation, phone 518-402-8165, email jmlendru@gw.dec.state.ny.us [will play a future role when responsibility for the NEIEN submission is transferred from the USC to the DEC].

\section{Pennsylvania}

Andy Zemba, Pennsylvania Department of Environmental Protection (PA-DEP), Office of Water Planning, Chesapeake Bay Program Director, P.O. Box 2063, 400 Market Street, 2nd Floor, Harrisburg, PA 17105-2063, phone 717-772-5633, email azemba@state.pa.us [supervises the PA-DEP's involvement with the Annual Progress Review].

Patricia A. Buckley, Chesapeake Bay Program Coordinator, Department of Environmental Protection (DEP)-Interstate Waters Office, Rachel Carson State Office Building, 400 Market Street, Harrisburg, PA 17101, phone 717-772-1675, email pbuckly@ pa.gov [leading discussions to establish a 1619 Conservation Cooperator Agreement between the PA-DEP and NRCS].

Ted Tesler, Pennsylvania Department of Environmental Planning, Water Planning Office, Chesapeake Bay Program Technical Lead, P.O. Box 2063, 400 Market Street, 2nd Floor, Harrisburg, PA 17105-2063, phone 717-772-5621, email thtesler@state. pa.us [receives aggregated conservation data from conservation program leads and submits the data to the PA-DEP Information Technology Department, who upload annual data to the Pennsylvania NEIEN node].

Barry Evans, Research Associate, Penn State Institute of Energy and the Environment, Director, GIS Support Center, 128 Land and Water Research, University Park, PA, phone 814-865-3357, email bme1@psu.edu [works as a contractor to the PA-DEP to assemble the dataset and format it for the NEIEN interface].

\section{Virginia}

Fred Garst, GIS Specialist, NRCS, phone 540-434-1401 ext. 125, email Fred.Garst@va.usda.gov [queries NRCS IDEA database to provide unaggregated data to Bill Keeling].

William Keeling, Non-point Source Modeling and Data Coordinator, Virginia Department of Conservation and Recreation (VADCR), Division of Storm Water Management, 203 Governor St., Richmond, VA 23219, phone 804-371-7485, email William. Keeling@dcr.virginia.gov [received data from Fred Garst, flags and removes potential double counting, delivered aggregated data to Karl Huber; after June 2013, will be working for the VA-DEQ and so this process may need alteration if Bill can no longer receive 1619 access to confidential datasets].

Karl Huber, Virginia Department of Conservation and Recreation (VA-DCR), 203 Governor St., Richmond, VA 23219-2049, phone 804-786-4356, email Karl.Huber@dcr.virginia.gov [receives data from Bill Keeling, formats it for NEIN submission, and submits the data to the Annual Progress Review via node client software].

Beverly Quinlan, Geoinformatics Specialist, VA-DCR, 203 Governor St., Richmond, VA 23219-2049, phone 804-371-0297, email beverly.quinlan@dcr.virginia.gov [pulled State financial assistance data from the State database and prepared it for NEIEN submittal using node client software].

Blaine Delaney, Chesapeake Bay Coordinator/Emergency Watershed Protection Program Coordinator, NRCS, 1606 Santa Rosa Road, Suite 209, Richmond, VA, 23229-5014, phone 804-287-1663, email Blaine.Delaney@va.usda.gov, Web site http://www. va.nrcs.usda.gov [involved in developing Virginia data reporting strategy]. 
Wade Biddix, Assistant NRCS State Conservationist (Programs), 1606 Santa Rosa Road, Suite 209 Richmond, VA 23229-5014, phone 804-287-1675, email Wade.Biddix@va.usda.gov [Fred Garst's supervisor, involved in developing Virginia data reporting strategy].

\section{West Virginia}

Matt Monroe, West Virginia Department of Agriculture (WVDA) Assistant Director, Moorefield Environmental Programs (Moorefield Ag Complex), phone 304-538-2397 ext. 6860, email mmonroe@wvda.us [has 1619 access to USDA data, provides aggregated implementation data to Alana Hartman].

Alana Hartman, West Virginia Department of Environmental Protection (WVDEP), Division of Water and Waste Management, Environmental Resources Analyst, Non-Point Source Program (Chesapeake Bay lead), 22288 Northwestern Pike, Romney, WV 26757, phone 304-822-7266 ext. 3623, email Alana.C.Hartman@wv.gov [submits records to NEIEN, does not have 1619 access to unaggregated USDA data].

Carla Hardy, West Virginia Conservation Agency (WVCA) Watershed Program Coordinator, Moorefield Field Office, 60 C Industrial Park Road, Moorefield, WV 26836, phone 304-538-7581, email chardy@wvca.us [the WVCA had previously established a 1619 Conservation Cooperator Agreement covering only Animal Waste Management and Mortality Disposal in the Potomac Basin; that agreement expired in March 2013 and was not planned to be renewed].

\section{Appendix B: 1619 Conservation Cooperator Agreements}

[Files are downloadable from http://pubs.usgs.gov/of/2013/1287/]

1_MDA_NRCS_1619_MOU.pdf. This is the 1619 agreement currently in place between the USDA and MDA.

2_NY_USC_NRCS_1619_Compliance_Agreement.pdf. This is the 1619 agreement currently in place between the USDA and the Upper Susquehanna Coalition.

3_VA_DCR_NRCS_1619_Attachment_C.pdf. The 1619 agreement currently in place between the USDA and VA-DCR. This agreement is signed separately by each VA-DCR staff person that has access to the USDA data.

4_WV_DA_NRCS_1619_Compliance_Agreement.pdf. The 1619 agreement currently in place between the USDA and WV DA.

5_WV_CA_2012_NRCS_TMDL_MOU_animals_only.pdf. The original 1619 agreement established between the USDA and WVCA. This agreement was renewed in 2013.

6_USGS_FSA_Signed_Agreement.pdf. The 1619 agreement currently in place between the USDA and USGS for FSA data.

7_USGS_NRCS_Signed_Agreement.pdf. The 1619 agreement currently in place between the USDA and USGS for NRCS data.

8_USGS_FSA_NRCS_Data_Handling_Procedures_Olivia.pdf. Example of a USGS data handling procedures agreement, which is signed by each USGS employee with access to the USDA data.

9_2012_Approval_for_bilateral_sharing_of_data_with_states.pdf. Email confirmation from the USDA that it is acceptable for the USGS to share USDA conservation data with jurisdictional 1619 USDA Conservation Cooperators.

10_Template_USDA_Section_1619_Cooperator_Memorandum_of_Understanding_for_Chesapeake_Bay_Agencies_September_2013.docx. Template 1619 Memorandum of Understanding that is recommended by FSA for use by Chesapeake Bay Watershed Initiative cooperating agencies. It includes comprehensive language that any single agency can adopt, including text to limit data access to specific individuals within an agency. 


\section{Appendix C: USGS-USDA Data Requests}

[Files are downloadable from http://pubs.usgs.gov/of/2013/1287/]

1_2012_USDA_Dataset_Field_Names.xlsx. List of data fields requested and received from the USDA in 2012.

2_2012_FSA_Data_Request.docx. Written data request for the 2012 FSA data including the Common Land Unit (CLU) and Conservation Reserve Program (CRP/CREP) farm records.

3_2012_NRCS_Chesapeake_Bay_Data_Request.pdf. Written data request for 2012 NRCS data.

4_2013_FSA_Data_Request.docx. Written data request for 2013 FSA data.

5_2013_NRCS_Data_Request.pdf. Written data request for 2013 NRCS data, specifying field names.

\section{Appendix D: USDA Practice Code Lookup Tables}

[Files are downloadable from http://pubs.usgs.gov/of/2013/1287/]

1_FSA_and_NRCS_Practice_List.xlsx. List of practices, practice code, units, and lifespan. This file also includes the overlapping practices between NRCS and FSA.

2_FSA_NRCS_Practice_Decoder_and_References_043012.xlsx. Tables linking similar NRCS and FSA practices.

\section{Appendix E: Crosswalk Between USDA Practice Codes and Scenario Builder}

[File is downloadable from http://pubs.usgs.gov/of/2013/1287/]

2012_NEIEN_USDA_Crosswalk.xlsx. File contains a “crosswalk" that translates between USDA practice codes and 2012 CBP Partnership approved conservation practices as defined in the NEIEN Appendix A.8.11. All NRCS and FSA practices that are implemented in the Chesapeake Bay Watershed were added to the NEIEN Appendix A.8.11. The first worksheet is the Appendix A.8.11. The second worksheet includes the comparison between land-based FSA and NRCS practices and the Appendix ID Code to which those practices map. The third worksheet includes a similar comparison for animal practices. 
ISSN 2331-1258 (online)

http://dx.doi.org/10.3133/ofr20131287 